\title{
NLC and the background atmosphere above ALOMAR
}

\author{
J. Fiedler, G. Baumgarten, U. Berger, P. Hoffmann, N. Kaifler, and F.-J. Lübken \\ Leibniz Institute of Atmospheric Physics at the Rostock University, Schloss-Str. 6, 18225 Kühlungsborn, Germany \\ Received: 13 January 2011 - Published in Atmos. Chem. Phys. Discuss.: 16 February 2011 \\ Revised: 20 May 2011 - Accepted: 6 June 2011 - Published: 21 June 2011
}

\begin{abstract}
Noctilucent clouds (NLC) have been measured by the Rayleigh/Mie/Raman-lidar at the ALOMAR research facility in Northern Norway $\left(69^{\circ} \mathrm{N}, 16^{\circ} \mathrm{E}\right)$. From 1997 to 2010 NLC were detected during more than $1850 \mathrm{~h}$ on 440 different days. Colocated MF-radar measurements and calculations with the Leibniz-Institute Middle Atmosphere (LIMA-) model are used to characterize the background atmosphere. Temperatures as well as horizontal winds at $83 \mathrm{~km}$ altitude show distinct differences during NLC observations compared to when NLC are absent. The seasonally averaged temperature is lower and the winds are stronger westward when NLC are detected. The wind separation is a robust feature as it shows up in measurements as well as in model results and it is consistent with the current understanding that lower temperatures support the existence of ice particles. For the whole 14-year data set there is no statistically significant relation between NLC occurrence and solar Lyman- $\alpha$ radiation. On the other hand NLC occurrence and temperatures at $83 \mathrm{~km}$ show a significant anti-correlation, which suggests that the thermal state plays a major role for the existence of ice particles and dominates the pure Lyman- $\alpha$ influence on water vapor during certain years. We find the seasonal mean NLC altitudes to be correlated to both Lyman- $\alpha$ radiation and temperature. NLC above ALOMAR are strongly influenced by atmospheric tides. The cloud water content varies by a factor of 2.8 over the diurnal cycle. Diurnal and semidiurnal amplitudes and phases show some pronounced year-to-year variations. In general, amplitudes as well as phases vary in a different manner. Amplitudes change by a factor of more than 3 and phases vary by up to $7 \mathrm{~h}$. Such variability could impact long-term NLC observations which do not cover the full diurnal cycle.
\end{abstract}

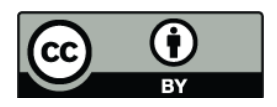

Correspondence to: J. Fiedler (fiedler@iap-kborn.de)

\section{Introduction}

More than 125 years ago unusual clouds, visible as twilight phenomena after sunset, were documented for the first time (Leslie, 1885; Backhouse, 1885; Jesse, 1885). While the surface of the Earth was already dark they appeared as striking glowing displays. The only explanation was illumination by the sun and it was clear that these clouds must be at exceptionally high altitudes. They were given the name noctilucent clouds (NLC) and by optical triangulation the altitude was determined to be around $82 \mathrm{~km}$ (Jesse, 1896). Since the beginning the clouds attracted the interest of a growing number of observers and it was realized that the bluish-white displays reoccurred every summer. However, it took about 50 years until naked eye observations of NLC were first summarized in a comprehensive work. Vestine (1934) showed that the maximum frequency of occurrence was about 10 days after summer solstice. Already in 1912 it was suggested that NLC are composed of ice particles (Wegener, 1912), which was finally proven by Hervig et al. (2001). NLC displays often show a rich variability, even on scales of a few kilometres, which provides information about dynamic processes like horizontal wind and wave motions in their environment (Witt, 1962). About 80 years after the initial observations the available information was compiled by Fogle and Haurwitz (1966). They pointed out that a relation between increased NLC activity and reduced solar activity, already suggested by Vestine (1934), cannot reliably be answered until a larger data set, covering a few sunspot cycles, will be available. Around that time the two longest-lasting NLC time series based on visual observations of the number of nights with cloud displays per season started: NW-Europe (Gadsden, 1989) and Moscow (Romejko et al., 2003). They now cover more than 4 decades.

Starting with the OGO-6 satellite, NLC are also detected from space (Donahue et al., 1972) and were later called polar mesospheric clouds (PMC) (Thomas, 1984). As both

Published by Copernicus Publications on behalf of the European Geosciences Union. 
names refer to the same phenomenon we will use the original notation (NLC) throughout the manuscript. Since 1979 the solar backscattered ultraviolet instruments (SBUV) onboard the NOAA satellites, operating from sun-synchronous orbits, observe the clouds on a regular basis by detecting an enhanced albedo (Thomas et al., 1991).

There is evidence that NLC consist of ice particles and are bound to very low temperatures around and below $150 \mathrm{~K}$ in combination with water vapor mixing ratios of only a few ppmv (e.g., Turco et al., 1982; Lübken et al., 1996; Berger and von Zahn, 2002; Rapp and Thomas, 2006). They are extremely sensitive to changes of these atmospheric background parameters, which are difficult to monitor with high accuracy, and may therefore serve as indicators for long-term changes (Thomas, 1996).

For both the NW-Europe and SBUV data sets, a mean anticorrelation between solar activity and NLC occurrence was shown (Kirkwood et al., 2008; Shettle et al., 2009). The SBUV time series shows this anti-correlation also with respect to NLC brightness and additionally an increasing trend of both occurrence and brightness (DeLand et al., 2007; Shettle et al., 2009). The robustness of these trends was disputed, partly based on the altitude of the clouds which seems to be unchanged since more the 100 years (von Zahn, 2003; Thomas et al., 2003). The virtually constant NLC altitudes were recently investigated by lidar observations covering roughly one decade (Fiedler et al., 2009).

Laser optical remote sensing has been a precise method to observe NLC for about 20 years. Lidar instruments have shown the variability of cloud occurrence and layer parameters on time scales from minutes to decades, including gravity wave, tidal and solar cycle variations (e.g., Thayer et al., 2003; Chu et al., 2003; Höffner et al., 2003; Fiedler et al., 2005; Gerding et al., 2007; Klekociuk et al., 2008). Multiwavelength and polarization techniques were successfully applied for NLC particle size and shape determinations (von Cossart et al., 1999; Alpers et al., 2000; Baumgarten et al., 2002, 2008).

A perfect instrument for NLC research would combine high accuracy with high temporal and spatial resolution and synoptic global coverage. Comparing ground-based lidar and satellite techniques it is obvious that each has advantages and disadvantages. Lidars maintain high temporal and vertical resolution as well as accuracy, but suffer from interruptions as they depend on the weather conditions and are limited to observations at fixed geographic locations. Satellite instruments can provide a global spatial mapping independent of tropospheric conditions, but only at fixed local times when on sun-synchronous orbits. Even when they precess, it takes weeks to cover a diurnal cycle.

In the following we will investigate the state of the atmosphere using lidar observations at the Arctic station ALOMAR. The observation of NLC at this geographic location began in 1989 and continues to the present day (Hansen et al., 1989; Langer et al., 1995; Nussbaumer et al., 1996). We in- vestigate a continuous time series starting 1997 which is the most extensive NLC data set obtained by lidar so far. Using model and radar data we will characterize the background atmosphere during our NLC observations and use model temperatures as proxy for the lidar sampling quality. An additional topic is year-to-year variations of tidal NLC parameters and possible implications on satellite-based time series.

\section{Data base}

For our investigations we use data obtained by lidar, radar, and model for the location of the Arctic Lidar Observatory for Middle Atmosphere Research (ALOMAR) facility in Northern Norway at $69^{\circ} \mathrm{N}, 16^{\circ} \mathrm{E}$.

\subsection{Lidar}

The ALOMAR Rayleigh/Mie/Raman-(RMR-) lidar is designed to operate on a routine basis throughout the year (von Zahn et al., 2000) and optimized for the detection of NLC. A combination of a spectral highly stable laser transmitter and strong spatial and spectral filtering at the receiving side allows NLC observations during highest solar elevations throughout the Arctic summer. The detector records laser photons backscattered from air molecules and NLC particles as a function of altitude $z$ as well as sunlight scattered by the atmosphere. After background subtraction the signal is converted to volume backscatter coefficient of NLC particles:

$\beta_{\mathrm{NLC}}(z)=(R(z)-1) \times \beta_{M}(z)$

using the backscatter ratio $R(z)$ as a measure for the presence of aerosol particles, which is defined as the ratio of the measured total signal to the molecular signal $\beta_{M}(z)$. From the altitude profile $\beta_{\mathrm{NLC}}(z)$ we determine the maximum value $\beta_{\max }$, the total backscatter coefficient $\beta_{\text {tot }}$ (integral over the vertical layer extension) and the centroid altitude $z_{c}$. For our investigations we use data obtained at $532 \mathrm{~nm}$ laser wavelength with an altitude/time resolution of $150 \mathrm{~m} / 14 \mathrm{~min}$. Detailed information regarding the data processing is given in Fiedler et al. (2009).

For better readability we will use the term "brightness" as synonym for $\beta_{\max }$ as well as $\beta_{\text {tot }}$ because the volume backscatter coefficient closely relates to the brightness which one would observe. Values of $\beta_{\max }$ will be given in units of $10^{-10} \mathrm{~m}^{-1} \mathrm{sr}^{-1}$, unless otherwise stated.

Signal and measurement uncertainty (determined from Poisson statistics of the photon counting process) at a given altitude depend on various processes, such as atmospheric transmission and system performance, and are consequently subject to variations from minutes to years. We introduce two data subsets to maintain sensitivity limits for NLC detection, which are determined by the mean measurement uncertainty $\Delta \beta_{\mathrm{NLC}}(z)$ in the altitude range from 


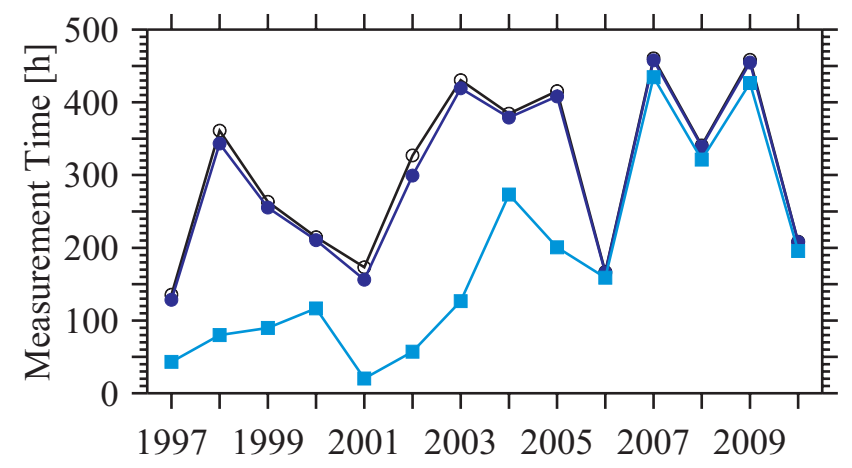

Fig. 1. Measurement times of the ALOMAR RMR-lidar during the NLC season (1 June-15 August) for different data sets: entire (black hollow circles), long-term (blue filled circles) and highsensitivity (light blue filled squares). The last two data subsets contain only measurements with mean uncertainties of $\Delta \beta_{\mathrm{NLC}}(z)<$ $4 \times 10^{-10} \mathrm{~m}^{-1} \mathrm{sr}^{-1}$ and $\Delta \beta_{\mathrm{NLC}}(z)<1 \times 10^{-10} \mathrm{~m}^{-1} \mathrm{sr}^{-1}$, respectively, in the altitude range from 80 to $90 \mathrm{~km}$.

80 to $90 \mathrm{~km}$ : the long-term data set contains only measurements with $\Delta \beta_{\mathrm{NLC}}(z)<4 \times 10^{-10} \mathrm{~m}^{-1} \mathrm{sr}^{-1}$, whereas the high-sensitivity data set is limited to measurements with $\Delta \beta_{\mathrm{NLC}}(z)<1 \times 10^{-10} \mathrm{~m}^{-1} \mathrm{sr}^{-1}$. Figure 1 shows the measurement times of the data subsets in comparison to the entire measurement time of the lidar. In total the signal quality is sufficient to determine potential NLC having $\beta_{\max }>4(>1)$ during $97 \%$ (59\%) of the time. Since 2006 both data subsets cover nearly the same amount of data which shows the increased sensitivity of the detection system achieved by replacing photomultiplier tubes with avalanche photodiodes.

From 1997 to 2010 the entire data set consists of $\sim 4340$ measurement hours where NLC were detected during $\sim 1865 \mathrm{~h}$ on $\sim 440$ different days. In the following sections we will use three lower brightness limits to classify NLC, which are used in combination with the appropriate data subset: $\beta_{\max }>1$ (=high-sensitivity limit, $63 \%$ of all NLC detections, high-sensitivity data set), $\beta_{\max }>4$ (= longterm limit, $55 \%$ of all NLC detections, long-term data set), $\beta_{\max }>13$ (= strong clouds, $16 \%$ of all NLC detections, longterm data set). Additionally we also introduce the following cloud classes: faint clouds $\left(\beta_{\max }: 1-4\right)$, weak clouds $\left(\beta_{\max }\right.$ : $4-7)$ and medium clouds ( $\left.\beta_{\max }: 7-13\right)$.

\subsection{Radar}

The ALOMAR MF-radar is designed for investigations of the dynamics of the mesosphere and lower thermosphere. It has continuously provided horizontal winds at altitudes between 70 and $94 \mathrm{~km}$ since 1998 using the full correlation analysis method. The radar operates at $1.98 \mathrm{MHz}$ and uses a vertically pointing wide beam antenna for the transmission of radio wave pulses of $4 \mathrm{~km}$ length. The atmospheric returns are received by three crossed horizontal dipoles arranged in an equilateral triangle. More details are given in Singer et al.
(1997). Wind values are derived with oversampling in height steps of $2 \mathrm{~km}$ and with a time resolution of $3 \mathrm{~min}$. We will use here hourly mean winds to characterize the dynamics at NLC altitudes.

\subsection{Model}

The Leibniz-Institute Middle Atmosphere (LIMA-) model is a circulation model of the middle atmosphere with special focus on the thermal structure around mesopause altitudes (Berger, 2008). LIMA is a fully non-linear, global, and 3-D Eulerian grid-point model which extends from the ground to the lower thermosphere $(0-150 \mathrm{~km})$ taking into account major processes of dynamics, radiation, chemistry, and transport. It implements a triangular horizontal grid structure with 41804 grid points in every horizontal layer $(\Delta x \sim \Delta y \sim 110 \mathrm{~km})$, and the adaptation of tropospheric and lower stratospheric data from ECMWF/ERA-40 up to altitudes of $35-40 \mathrm{~km}$ every $6 \mathrm{~h}$. This introduces a coupling of the model results in the mesopause region to the wave activity from planetary to tidal to gravity wave scales in tropoand stratosphere. The current version of LIMA also includes the spectral solar irradiance from the ultraviolet to the near infrared relative with Lyman- $\alpha$ variability (taken from http://lasp.colorado.edu/lisird/lya/) according to Lean et al. (1997). We will use LIMA results of temperature and horizontal winds for characterization of the background atmosphere. The time resolution is $1 \mathrm{~h}$, until otherwise stated.

\section{Year-to-year variations and sampling quality}

For ground-based lidar measurements clear sky is needed and hence they depend on the weather conditions. For this reason a single year of our NLC data base is a rather patchy time series representing clear sky conditions above ALOMAR. Between 1 June and 15 August the total measurement times cover about $25 \%$ of the maximum possible time during good years and drop down to about $7 \%$ during bad years. This could bias the statistical robustness of long-term time series because all cloud parameters show variations with season and local time. Fiedler et al. (2009) investigated the reliability of the NLC occurrence time series by randomly choosing data subsets as well as taking into account the conservation tendency of geophysical data. The results confirmed the general year-to-year variation pattern obtained from the entire data set.

Here we use a different method to estimate the impact of unequal sampling on the seasonal mean values of the NLC parameters (occurrence, altitude, brightness). The 14-years mean seasonal and local time variations of a parameter are used to calculate the expected seasonal mean value for each year using the actual observation times of the particular year. The deviation between expected and actually measured seasonal mean values is regarded as sampling quality. 
To characterize the mean variations we use updated values, covering the range from 1997 to 2010, for the parametrizations given in Fiedler et al. (2005, 2009). The seasonal variations are characterized by third-order polynomial fits. Local time variations are described by harmonic fits using periods of $24,12,8$ and $6 \mathrm{~h}$ :

$$
\begin{aligned}
& \operatorname{DOY}(d)=a_{0}+a_{1} d+a_{2} d^{2}+a_{3} d^{3} \\
& \operatorname{LT}(t)=A_{0}+A_{24} \cos \left[\frac{2 \pi}{24}\left(t-\phi_{24}\right)\right]+A_{12} \cos \left[\frac{2 \pi}{12}\left(t-\phi_{12}\right)\right]+\ldots
\end{aligned}
$$

where $a$ are the fit coefficients, $d$ is day relative to solstice, $A_{0}$ is the mean value, $A$ and $\phi$ are the amplitudes and phases of the wave components and $t$ is local time in hours.

The following method is applied to each NLC parameter, because occurrence, altitude and brightness show different variation patterns over season as well as local time. At first the two individual fits (DOY, LT) are calculated and normalized to their mean values $\overline{\mathrm{DOY}}$ and $\overline{\mathrm{LT}}$. This yields the relative variation of the NLC parameter. Given a full temporal sampling of a fit curve ( 76 days per season, $24 \mathrm{~h}$ per day), the resulting mean value would be equal to one. Then for each day and hour of the season the contributions of seasonal and local time variations are combined by multiplying daily and hourly relative variations:

$\operatorname{FIT}_{\text {rel }}(d, t)=\frac{\operatorname{DOY}(d)}{\overline{\mathrm{DOY}}} \times \frac{\mathrm{LT}(t)}{\overline{\mathrm{LT}}}$

Again, the mean value of this overall fit curve $F I T_{\text {rel }}$ equals one. The result is shown in Fig. 2. We determine the effect of a non-perfect sampling in each year as follows: we

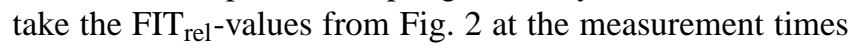
in a specific year and determine the mean of these $\mathrm{FIT}_{\text {rel- }}{ }^{-}$ values, which we call the "relative sampling factor" RSF. This factor is an estimate of the bias introduced by the sampling effect and is shown in Fig. 3 (left panels). For example, $\mathrm{RSF}=1.1$ for the occurrence frequency in 2004 means that the mean occurrence frequency calculated in that year is probably overestimated by $10 \%$ due to sampling effects. Note that this method assumes temporal variations of the same type during each year which is doubtless only an approximation of the (unknown) actual conditions.

For the long-term data set the uncertainties introduced by unequal sampling are roughly $\pm 10 \%$ for occurrence and brightness. The uncertainty of NLC altitudes is smaller by a factor of $\sim 100$, which is caused by the small altitude variability over season and local time. The uncertainties for the high-sensitivity data set are generally larger because of the reduced amount of data. We notice that the years showing the worst sampling quality are not identical for each parameter. While in 2005 the occurrence was overestimated by $25 \%$, the values for altitude and brightness are rather small. On the other hand RSF for altitude shows maxima during 2001 and 2002. This is caused by the different variation patterns of the parameters over season and local time shown in Fig. 2. It is
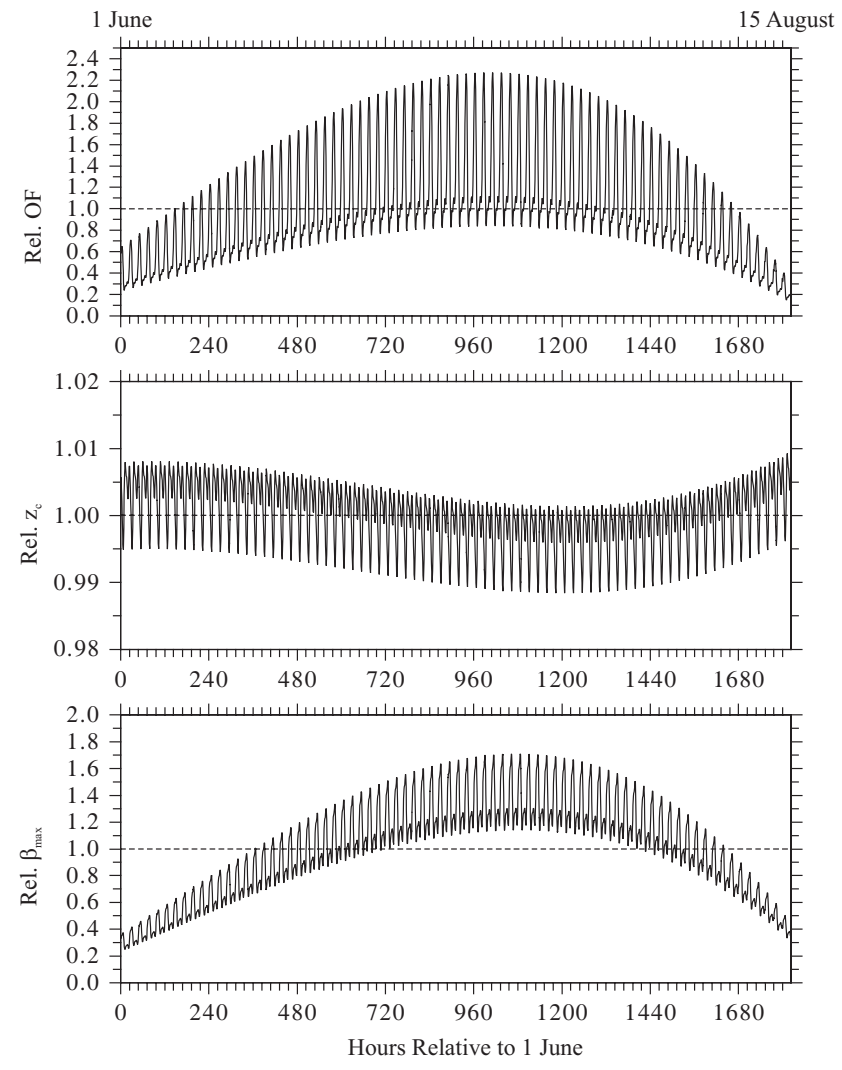

Fig. 2. Hourly relative variations of NLC occurrence (top), altitude (middle) and brightness (bottom) as determined from fit coefficients for the integrated ALOMAR RMR-lidar data set from 1997 to 2010. For details see text. In Fig. 4 the local time variations are shown with higher resolution.

interesting to note that years with a small amount of data do not necessarily show a bad sampling quality. The measurement time in 2006 was only $36 \%$ compared to 2007 but the uncertainties of all parameters introduced by unequal sampling hardly differ from each other. The sampling qualities of both data sets (long-term and high-sensitivity) are almost identical since 2006, which is caused by technical improvements of the lidar system, and differ from each other in the years before.

Figure 3 shows on the right panels the time series of NLC occurrence, altitude and brightness, each for clouds above the high-sensitivity limit $\left(\beta_{\max }>1\right)$, above the long-term limit $\left(\beta_{\max }>4\right)$ as well as strong clouds $\left(\beta_{\max }>13\right)$. The solid curves result from the regular data processing, the dashed curves are corrected regarding the sampling quality by normalization to RSF-values. It turns out that for each NLC parameter the general variation patterns of the long-term data set are not significantly affected by the sampling. The deviations are larger for the high-sensitivity data set. Until 2003 the confidence limits of the NLC occurrence for clouds having $\beta_{\max }>1$ are enhanced due to the weak measurement statistics within the high-sensitivity data set. 

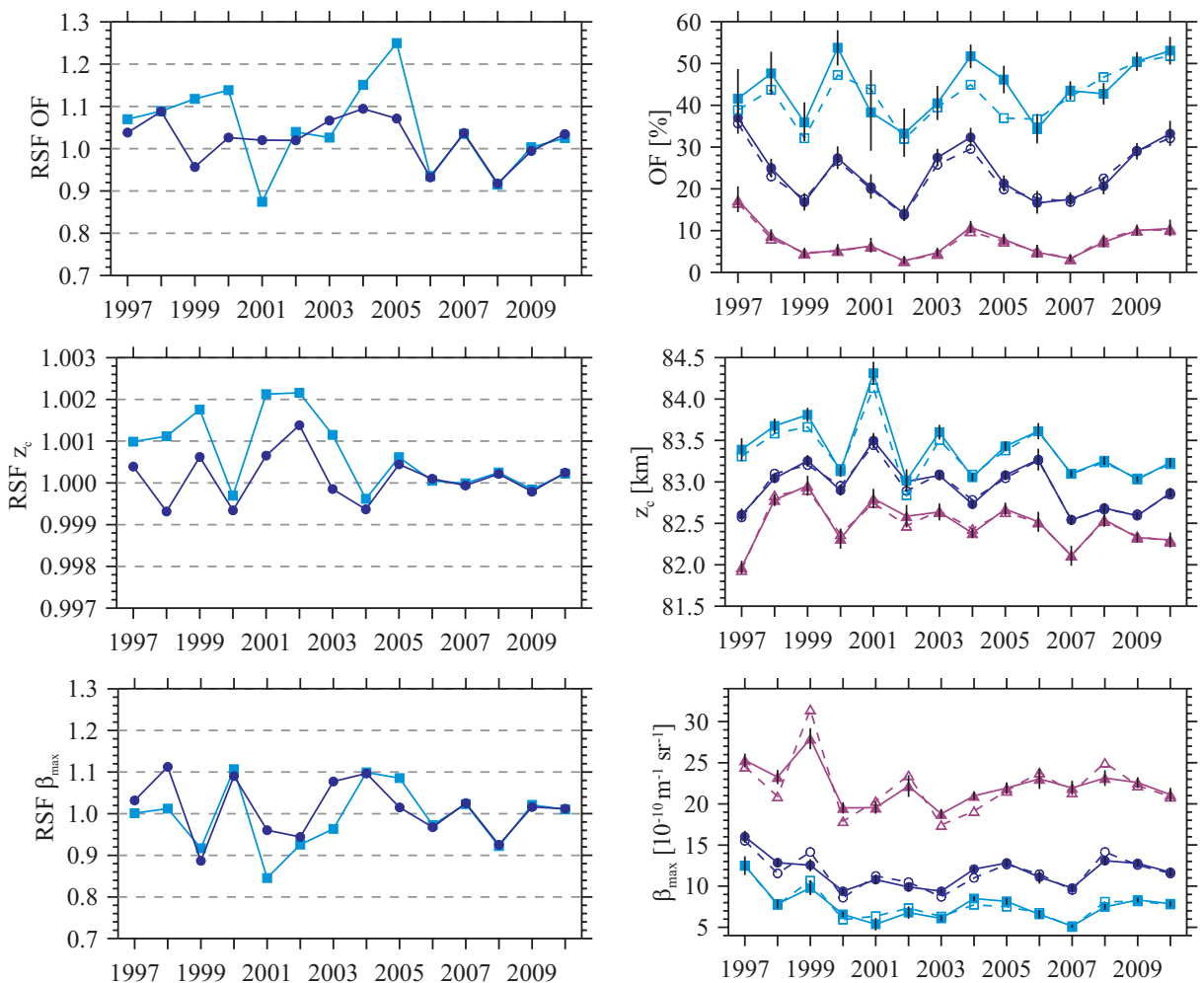

Fig. 3. Seasonal mean relative sampling factors RSF (left) and mean values (right) of NLC occurrence (top), altitude (middle) and brightness (bottom). Sampling curves are calculated for two data sets: long-term (blue circles) and high-sensitivity (light blue squares). Curves at the right side are for three brightness classes: $\beta_{\max }>1$ (light blue squares), $\beta_{\max }>4$ (blue circles), $\beta_{\max }>13$ (purple triangles). Dashed lines and open symbols are corrected regarding the sampling quality. Vertical bars indicate confidence limits for the occurrence at $95 \%$-level and errors of the means for altitude and brightness.

The general variation patterns are fairly similar for the three brightness classes, but at different mean levels. A detailed discussion of the year-to-year variability until 2007 can be found in Fiedler et al. (2009). We conclude that the sampling influence on our measurements is rather weak and will use the results without corrections during the next sections.

\section{Local time variations}

The mean diurnal variations of NLC occurrence, altitude and brightness over 14 years are shown in Fig. 4. All three time series, i.e. clouds above the high-sensitivity limit $\left(\beta_{\max }>1\right)$, above the long-term limit $\left(\beta_{\max }>4\right)$ as well as strong clouds $\left(\beta_{\max }>13\right)$, show similar patterns but on different mean levels. There are pronounced persistent features indicating strong tidal influences on ice particles above ALOMAR, which has been shown earlier (Fiedler et al., 2005). NLC occur most frequently in the morning hours and most seldom around noon. The magnitude of occurrence frequency variation over the diurnal cycle increases with brightness limit: factor 2.0 for $\beta_{\max }>1$, factor 3.1 for $\beta_{\max }>4$ and factor 8.9 for $\beta_{\max }>13$. The altitude is lowest around 08:00 LT and highest during midnight and the early afternoon, the variabil- ity range during day is about $1 \mathrm{~km}$. NLC are generally less bright from noon to midnight compared to the first half of the day.

We have investigated the year-to-year variations of the tidal components. To enhance the statistical robustness we calculated running means of the NLC parameters, covering three years each. Harmonic fits to the data have been done using the method described in Sect. 3. Fit coefficients are determined considering errors of the hourly means by applying a Levenberg-Marquardt-algorithm. The so-called reduced Chi-square value describes the quality of least squares fits and should be around one. The mean value of all our fits is $1.3 \pm 0.8$ which indicates that fit model and data are in good agreement. Eight and $6 \mathrm{~h}$ periods have generally smaller amplitudes than 24 and $12 \mathrm{~h}$ periods and could be caused by geophysics, such as wave-wave interactions of tidal components or gravity waves. However, they presumably depend more on sampling issues than the longer periods. In the following we will investigate only the diurnal and semidiurnal components.

Figure 5 shows for clouds above the long-term limit the year-to-year variations of amplitudes and phases for 24- and 12-h periods of occurrence, altitude and brightness. Data 

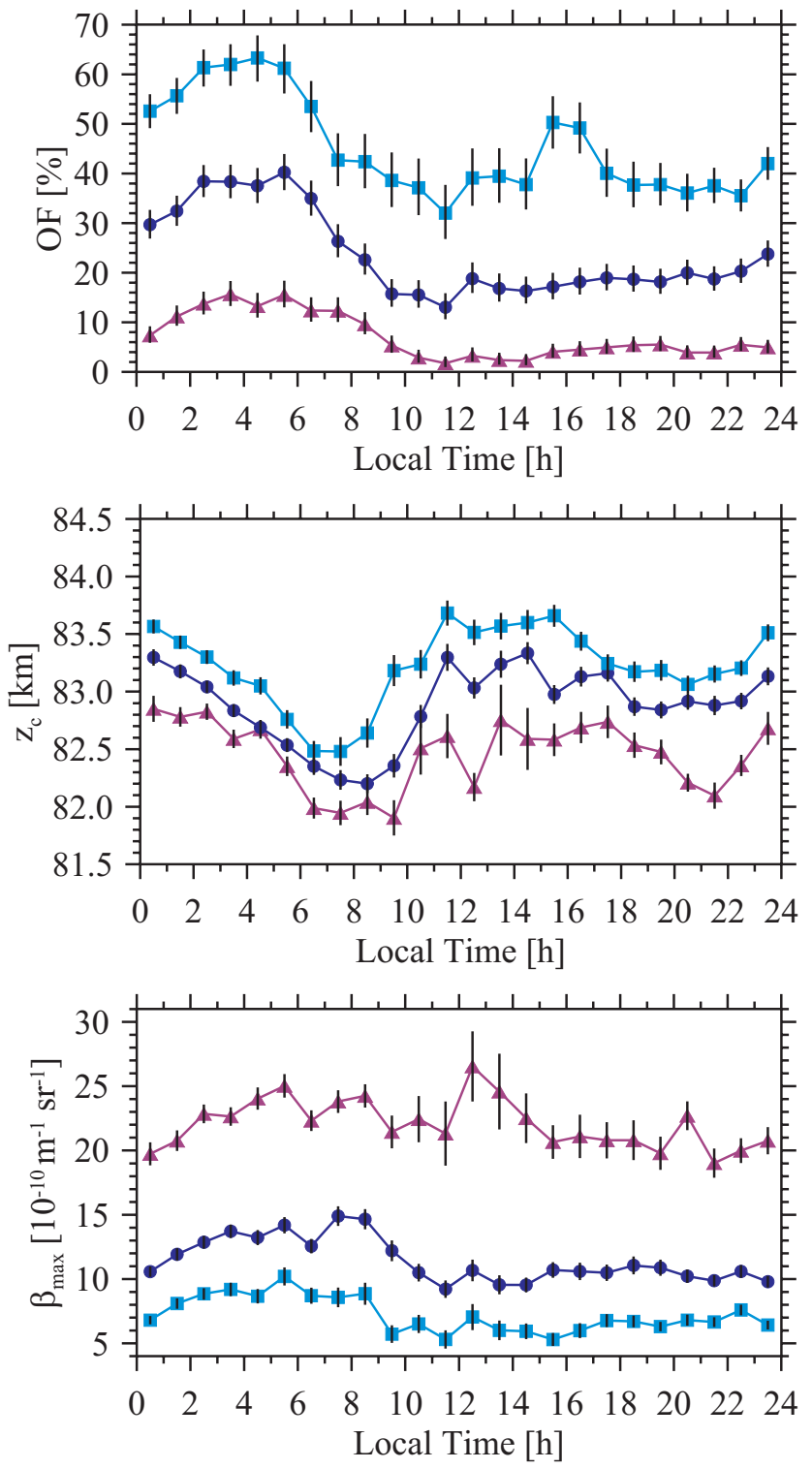

Fig. 4. Diurnal variation of NLC occurrence (top), altitude (middle) and brightness (bottom) for the integrated data set from 1997 to 2010 , sorted by brightness classes: $\beta_{\max }>1$ (light blue squares), $\beta_{\max }>4$ (blue circles), $\beta_{\max }>13$ (purple triangles). Vertical bars indicate confidence limits for the occurrence at $95 \%$-level and errors of the means for altitude and brightness.

points are based on running means and plotted at the center of the corresponding 3 years range.

The diurnal and semidiurnal phases of the NLC occurrence are quite stable around 04:00 LT, which is the underlying reason for the NLC recurrence maximum in the morning hours. The diurnal amplitude is stronger than the semidiurnal during each year and decreases by about 50\% from 1999 to 2007 .

The phases of the NLC altitude are separated by about $6 \mathrm{~h}$ and vary by only about $3 \mathrm{~h}$ during 14 years. The amplitudes of both components increase more or less steadily by about
$100 \%$ until 2006 and decrease again thereafter. During half of all years diurnal and semidiurnal amplitudes are approximately equal, the other years are dominated by the semidiurnal component.

For brightness $\left(\beta_{\max }\right)$ the semidiurnal phase is almost constant around 06:30 LT until 2004 and decreases thereafter by about $4.5 \mathrm{~h}$. The diurnal phase shows a nearly monotonic increase from 1998 to 2009 by about $7 \mathrm{~h}$. This phase shift is a striking feature of the time series and is also visible when using $\beta_{\text {tot }}$ for characterization of the NLC brightness. The anti-correlation of the tidal oscillations of altitude and brightness (Fiedler et al., 2005) deteriorates from the first to the second half of the 14-years data set $(r=-0.77$ from 1997 2003, $r=-0.68$ from 2004-2010), but is still significant on $99 \%$ level. The diurnal amplitude decreases strongly after 2005. The semidiurnal amplitude shows maximum values at 1998 and 2006 and a deep distinct minimum in between, which is centered around 2001.

In summary we note that some tidal parameters are fairly constant in time (e.g. $24 \mathrm{~h}$ phase of occurrence), whereas others vary substantially (e.g. $12 \mathrm{~h}$ amplitude of brightness).

\section{Atmospheric background conditions during observations}

Ice particles in the mesopause region react sensitively to their atmospheric background, especially temperature and water vapour. This has been shown by numerous models, cf. Turco et al. (1982); Rapp and Thomas (2006). In the presence of water vapour the main driving parameter for the existence and properties of NLC is temperature. Seasonal mean temperature variations at NLC altitudes are calculated to be up to $3 \mathrm{~K}$ over a solar cycle (Schmidt et al., 2006; Marsh et al., 2007). Over the summer season temperatures have been measured to change by about $7 \mathrm{~K}$ (Lübken, 1999). Gravity wave activity can cause variations of $\sim 15 \mathrm{~K}$ within a few hours (Rauthe et al., 2006).

In Berger (2008) it was shown that LIMA produces reasonable temperatures on annual scales, based on daily means. Here we investigate how results from the LIMA-model are related to NLC observations above ALOMAR. Figure 6 shows the NLC time series obtained during three days of continuous lidar measurements early in July 2005 as well as the calculated fields for temperature and horizontal winds. Time resolution for both RMR-lidar and LIMA data is $\sim 150$ seconds. To see more details, for temperature and zonal wind also the deviations from the three days mean altitude profiles are shown. At $83 \mathrm{~km}$ the temperature mean (range) is about $148 \mathrm{~K}( \pm 4 \mathrm{~K})$. The zonal wind is always westward directed with a mean (range) of about $-44 \mathrm{~m} / \mathrm{s}$ $( \pm 18 \mathrm{~m} / \mathrm{s})$. The meridional wind changes direction in the course of the day between about $-15 \mathrm{~m} / \mathrm{s}$ and $+10 \mathrm{~m} / \mathrm{s}$, resulting in a small mean value of $-0.5 \mathrm{~m} / \mathrm{s}$. To link the 

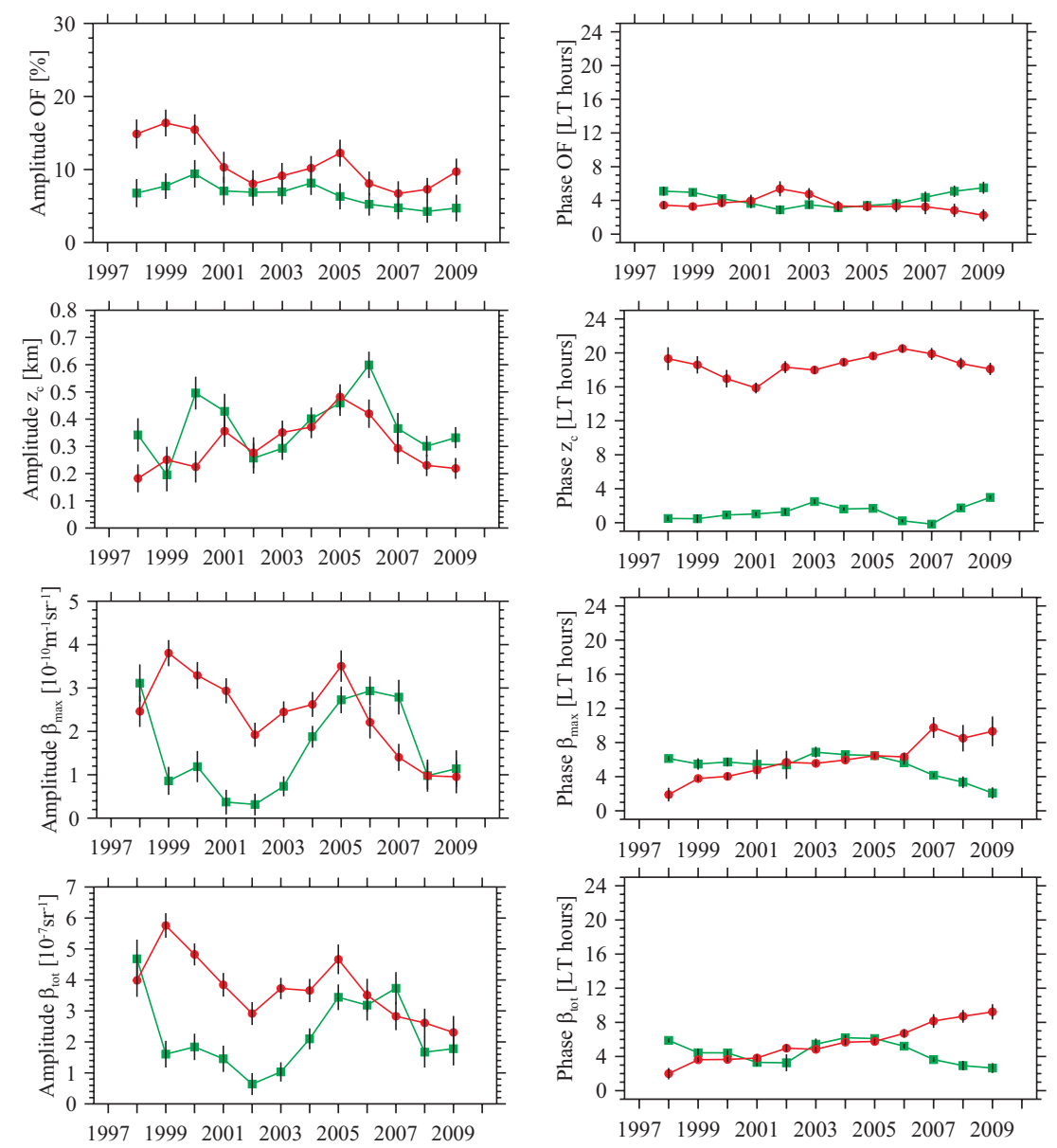

Fig. 5. Year-to-year variations of seasonal mean amplitudes and phases for 24- (red circles) and 12-h (green squares) periods of NLC parameters. From top to bottom: occurrence, altitude, brightness $\left(\beta_{\max }\right)$, brightness $\left(\beta_{\mathrm{tot}}\right)$. Based on 3 years running means for clouds above the long-term limit. Vertical bars are errors resulting from Levenberg-Marquardt least-squares fits.

observations with the model, the NLC contours for a brightness of $\beta_{\max }=4$ are plotted on top of the LIMA results.

As can be seen, within these three days NLC occur almost exclusively during the cold phases of the temperature anomalies and mostly during periods of enhanced westward winds. For meridional winds the picture is ambiguous as NLC were observed both during southward and northward winds.

In a next step we use the whole data base of RMR-lidar measurements from 1997 to 2010 in order to check if the agreement found above is statistically robust. For that, seasonal mean values of temperature and horizontal winds at $83 \mathrm{~km}$ altitude above ALOMAR are calculated with LIMA for times of confirmed absence as well as presence $\left(\beta_{\max }>4\right)$ of NLC within the lidar long-term data set. LIMA results are based on hourly means. The result is shown in Fig. 7. During each single year it is colder and the westward winds have been stronger during NLC observations compared to the absence of NLC. This separation also shows for the meridional wind, but not during all years.
Average values and standard deviations over 14 years for temperature, zonal and meridional wind at $83 \mathrm{~km}$ during NLC presence $\left(\beta_{\max }>4\right)$ are $147.6 \mathrm{~K} \pm 2.3 \mathrm{~K},-44.2 \mathrm{~m} / \mathrm{s}$ $\pm 11.0 \mathrm{~m} / \mathrm{s}$ and $-3.3 \mathrm{~m} / \mathrm{s} \pm 9.4 \mathrm{~m} / \mathrm{s}$, respectively. The $14-$ years mean differences between NLC presence and absence are $-2.0 \mathrm{~K}$ for temperature, $-9.1 \mathrm{~m} / \mathrm{s}$ for zonal wind and $-2.5 \mathrm{~m} / \mathrm{s}$ for meridional wind. The pronounced differences between NLC presence and absence are also visible with respect to local time for temperature and zonal wind, and to a lesser extent for the meridional wind (not shown here).

Figure 7 also shows horizontal winds obtained by the ALOMAR MF-radar, which has observed mesospheric winds since 1999 on a regular basis. The seasonal means have been processed in the same way like the LIMA winds, namely based on hourly means and sorted for NLC yes/no cases. Average values and standard deviations (representing the geophysical variability) over 12 years for zonal and meridional wind at $83 \mathrm{~km}$ during NLC presence $\left(\beta_{\max }>4\right)$ are $-27.6 \mathrm{~m} / \mathrm{s} \pm 14.8 \mathrm{~m} / \mathrm{s}$ and $-6.9 \mathrm{~m} / \mathrm{s} \pm 15.0 \mathrm{~m} / \mathrm{s}$, respectively. The 12 -years mean differences between NLC 


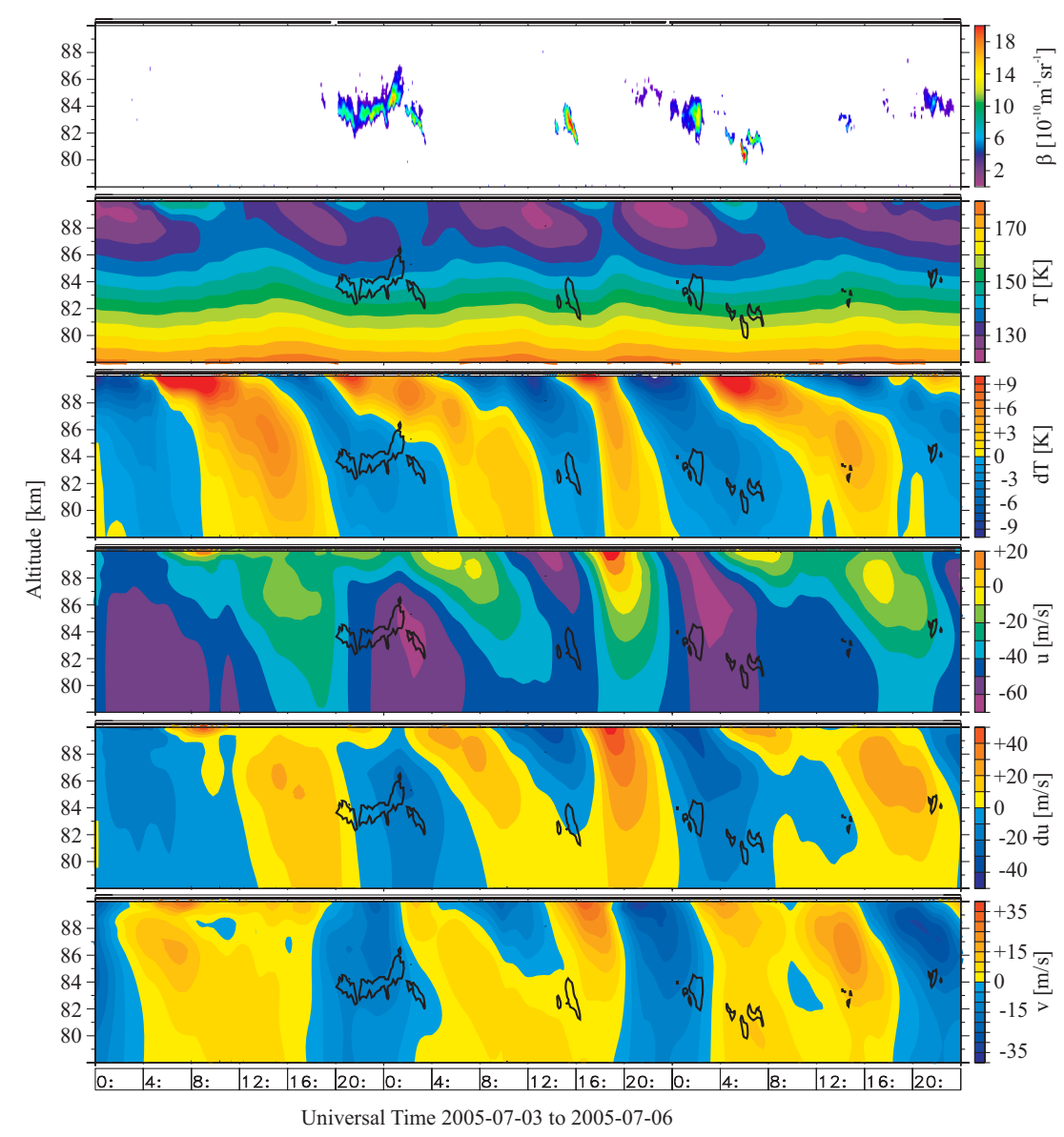

Fig. 6. Time series for NLC (measured by RMR-lidar) and atmospheric parameters (calculated by LIMA-model) for three consecutive days (3-5 July 2005) above ALOMAR. From top to bottom: NLC brightness in terms of volume backscatter coefficient, temperature, temperature deviation, zonal wind, zonal wind deviation, and meridional wind. Deviations are calculated with respect to the mean profiles over the whole time period. NLC contours for a brightness of $\beta_{\max }=4$ are plotted on top of the LIMA results. At $83 \mathrm{~km}$ the mean values (ranges) for temperature, zonal wind and meridional wind are about: $148 \mathrm{~K}( \pm 4 \mathrm{~K}),-44 \mathrm{~m} / \mathrm{s}( \pm 18 \mathrm{~m} / \mathrm{s}),-0.5 \mathrm{~m} / \mathrm{s}( \pm 12 \mathrm{~m} / \mathrm{s})$.

presence and absence are $-10.5 \mathrm{~m} / \mathrm{s}$ for zonal wind and $-4.6 \mathrm{~m} / \mathrm{s}$ for meridional wind. During particular years the zonal wind during NLC absence can remarkably deviate from the usual summer westward wind regime.

Firstly, we note that geophysical variabilities are on the order of, or even larger than, the differences between NLC presence and absence. The meridional wind shows a particularly high variability caused by the direction reversals during the day. Secondly, absolute wind values are different for LIMA and MF-radar, especially for the zonal wind, which however does not matter for our considerations. Much more important, the pronounced pattern of stronger westward winds during NLC presence versus absence is in evidence. Like in the LIMA results, this is to a lesser extent visible in the meridional winds. Differences in year-to-year wind variations between model and measurement are at least partly caused by unequal time coverage as the atmospheric scatter conditions for the MF-radar method are not always sufficient for wind determinations.
We conclude that the wind separation into NLC yes/no cases is a robust feature as it shows up in measurement as well as model. The feature of lower temperatures calculated by LIMA during measured NLC presence compared to absence appears plausible from an ice particle's point of view. In combination with the wind results we conclude that LIMA seems to reproduce the background atmosphere to a sufficient degree even on hourly resolution.

\section{Discussion}

In Sect. 5 we have shown that LIMA produces reasonable results on an hourly basis, namely meaningful temperature differences and by measurements approved wind differences for NLC presence/absence in the RMR-lidar data. The temperature and horizontal wind differences between presence/absence of NLC show that the local atmospheric conditions contribute considerably to the existence of ice particles. This is supported by model calculations. Berger and von 

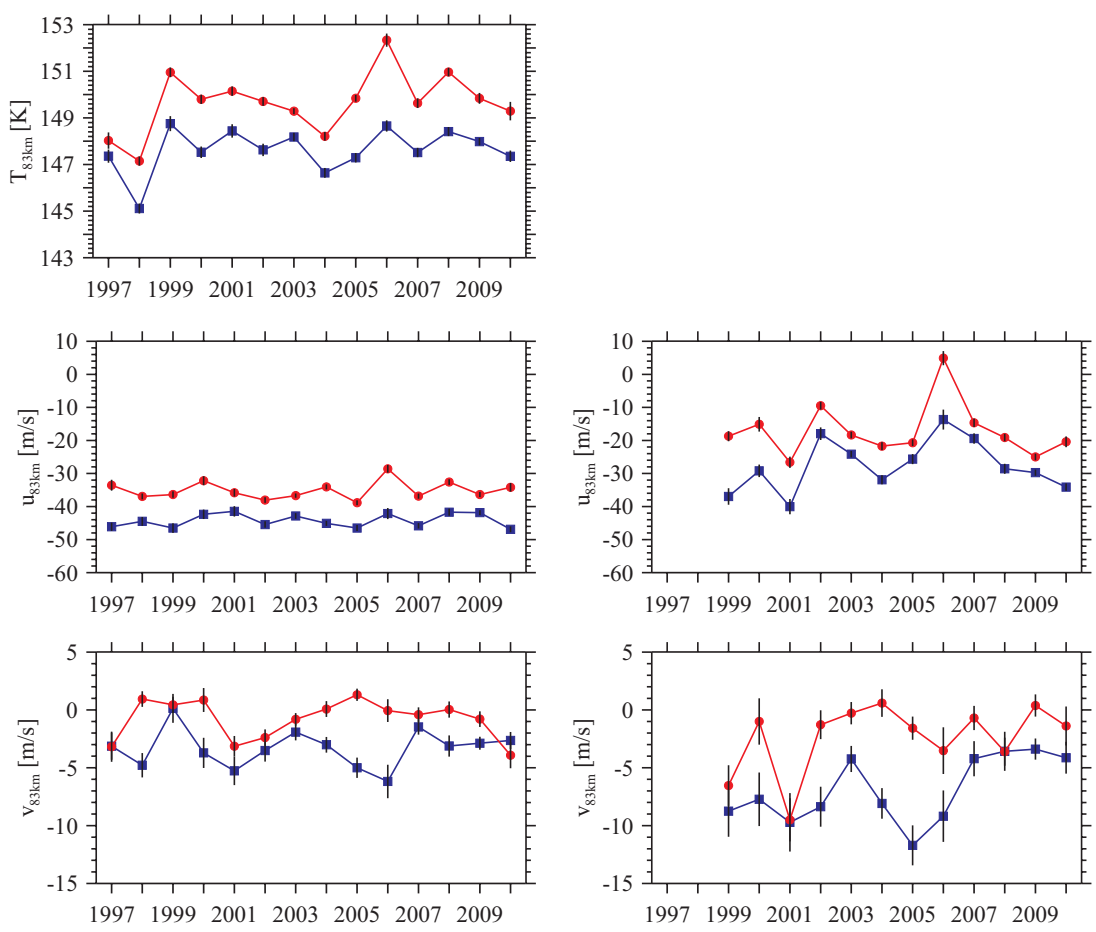

Fig. 7. Seasonal mean temperature (top), zonal (middle) and meridional (bottom) wind at $83 \mathrm{~km}$ altitude above ALOMAR as calculated by the LIMA-model (left) and measured by the ALOMAR MF-radar (right). Data are based on hourly mean values. Only hours with ALOMAR RMR-lidar measurements are taken into account (long-term data set). Data are separated for confirmed absence (red circles) and presence $\left(\beta_{\max }>4\right.$, blue squares) of NLC. Vertical bars are error of the means.

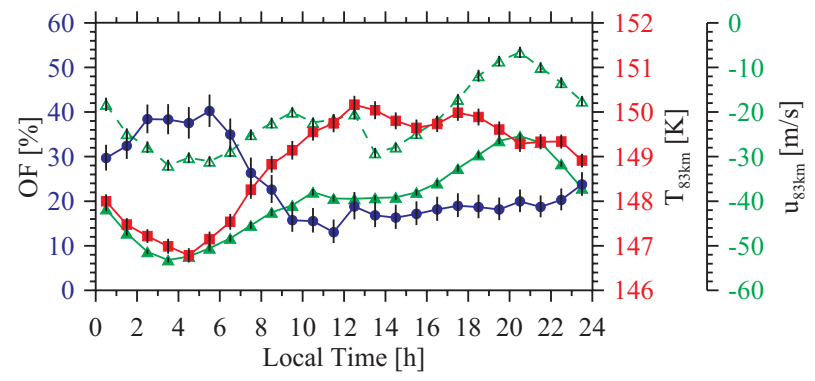

Fig. 8. Diurnal variation of NLC occurrence determined from ALOMAR RMR-lidar ( $\beta_{\max }>4$, blue circles) and atmospheric parameters at $83 \mathrm{~km}$ altitude during times of lidar measurements: temperature (red squares) and zonal wind (green filled triangles) as calculated by LIMA, zonal wind measured by the MF-radar (green open triangles, dashed line). RMR and LIMA data are integrated from 1997 to 2010, MF data from 1999 to 2010. Vertical bars indicate confidence limits for the occurrence at $95 \%$-level and errors of the means for temperature and wind.

Zahn (2007) showed that the most likely transport time of an NLC particle from nucleation to a radius larger than $50 \mathrm{~nm}$ is about $30 \mathrm{~h}$. Particle trajectories calculated by LIMA/ICE additionally indicate that especially the last $4-6 \mathrm{~h}$ of the particle lifetime are essential for maximum ice growth (Kiliani et al., 2011).
The relation between temperature and NLC seems plausible as lower temperatures support the existence of ice particles. Southward winds will usually transport the particles from colder regions further north towards ALOMAR (Berger and von Zahn, 2007). However, the relationship between stronger westward winds and enhanced NLC occurrence is not readily obvious. We note that in Fig. 6 the anomalies of temperature and zonal wind are in phase most of the time, i.e. lower temperatures coincide with enhanced westward winds. Figure 8 shows the diurnal variations of LIMA temperatures and zonal winds at $83 \mathrm{~km}$ altitude during times of lidar measurements for the integrated data set from 1997 to 2010 . It turns out that on multi-year average the strongest westward winds occur in the early morning around $4 \mathrm{~h}$ local time, like the temperature minimum and the NLC occurrence maximum. Thus the tidal behavior appears responsible to a large extent for the coincidences. The zonal wind variation pattern calculated by LIMA is confirmed by the MF-radar results, which show the same phases but on a different mean level (cf. Sect. 5). The anti-correlation between LIMA temperature and NLC occurrence $\left(\beta_{\max }>4\right)$ is almost perfect $(r=-0.96$, $99 \%$-level). The mean temperature variation during the day is $3.4 \mathrm{~K}$. This is less than half of the daily variability shown in Fig. 6 which is mainly caused by averaging over 14 NLC seasons. 

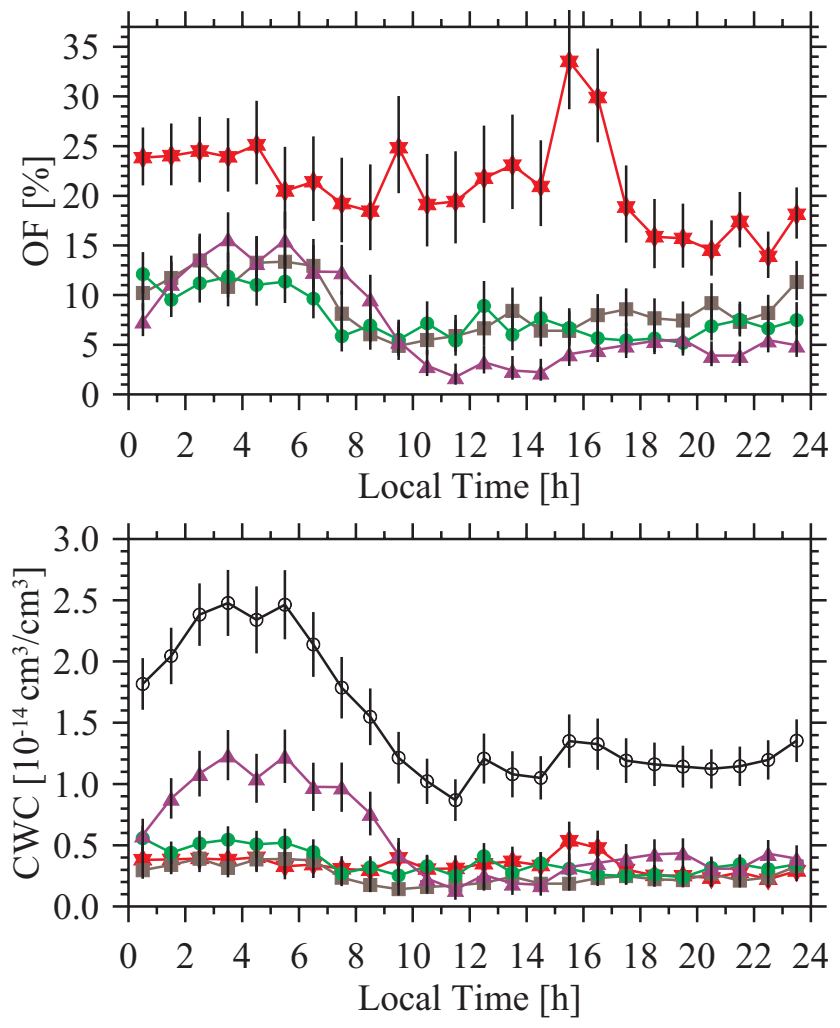

Fig. 9. Diurnal variation of NLC occurrence (top) and cloud water content CWC (bottom) determined from ALOMAR RMR-lidar measurements for the integrated data set from 1997 to 2010. Data for faint (red stars), weak (brown squares), medium (green filled circles) and strong (purple triangles) clouds are shown. The black curve (open circles) at the lower panel is the integrated CWC over all cloud classes. Vertical bars indicate confidence limits for the occurrence at $95 \%$-level and errors of the means for CWC.

Stevens et al. (2010) reported comparable strong relations between temperature at $83 \mathrm{~km}$ and ice particles. Using a global numerical weather prediction system that assimilates satellite temperature and water vapor observations from ground to $90 \mathrm{~km}$ altitude, they found the migrating diurnal temperature tide at $69^{\circ} \mathrm{N}$ to control the variation of NLC total ice water content over the diurnal cycle. The ice water content is calculated to vary by a factor larger than 5 with maximum values between 05:00 and 08:00 LT. To address the diurnal variations of water/ice mass we apply a method used earlier for our lidar data set, which is described in detail in Baumgarten et al. (2008). It is based on the mean cloud water content (CWC) for faint, weak, medium and strong clouds. The amount of water per cloud class is described by the ice volume density $V_{\text {class }}$ obtained from our 3-color NLC observations, which are a subset of the observations investigated here. The cloud water content is then calculated from $V_{\text {class }}$ and the corresponding occurrence frequencies $\mathrm{OF}_{\text {class }}$ using $\mathrm{CWC}_{\text {class }}=\mathrm{OF}_{\text {class }} \times V_{\text {class }}$. Figure 9 shows the diur- nal variations of NLC occurrence frequencies and CWC for faint, weak, medium and strong clouds for the integrated data set from 1997 to 2010. Faint clouds occur most often compared to the other cloud classes but the occurrence variability is largest for strong clouds. As strong clouds carry 5 times more water than faint clouds this behavior causes the strong clouds to determine most of the CWC variability over the diurnal cycle: CWC varies by a factor of 8.9 for solely strong clouds, but only by a factor of 2.8 when integrating over all cloud classes.

\subsection{Sampling quality}

An important topic for interpretation of real time series which do not cover all local times and geographic locations is, how the measured value differs from the "true" one. Inherently this question cannot be answered from itself. Comparing actual results with the long-term mean behavior is one approach, which we have used in Sect. 3. The result showed that the influence of unequal temporal sampling over season and diurnal cycle is rather small when using the mean seasonal and diurnal variations of 14 years for reference. Another possibility is the usage of a different parameter, which is strongly related to the virtual one and additionally always available, as proxy for missing measurements. We will here use the LIMA temperatures at $83 \mathrm{~km}$ altitude as proxy for times when we lack lidar measurements to investigate the sampling quality regarding the time dependent temperature field above ALOMAR. Seasonal means from LIMA obtained solely for hours with lidar measurements are compared to entire means from $1 \mathrm{June}$ to $15 \mathrm{Au}$ gust. The result is shown in Fig. 10. For the long-term data set the deviations from the entire seasonal means range between $+0.5 \mathrm{~K}$ and $-0.9 \mathrm{~K}$. During each individual year these values are smaller than the ones resulting from the NLC yes/no separation, c.f. Fig. 7. The 14-years mean deviation is close to zero $(-0.09 \mathrm{~K} \pm 0.12 \mathrm{~K})$. The deviations for the high-sensitivity data set are larger during the first years due to the weaker measurement statistics. The 14-years mean deviation is $-0.31 \mathrm{~K} \pm 0.13 \mathrm{~K}$. Despite the different amount of measurement hours the deviations for 2006 and 2007 are nearly identical, cf. Sect. 3 . Generally we find no significant correlation between sampling quality and NLC occurrence when using LIMA temperatures above ALOMAR as proxy.

\subsection{Tidal parameters}

We find minimum values for the semidiurnal amplitude of NLC brightness during solar maximum (2001-2003), cf. Fig. 5. The correlation coefficient for the time range from 1998-2007 is -0.88 , which indicates sufficient significance even when considering the 3 -years running mean filter. There are virtually no investigations regarding the interrelation between solar radiation and semidiurnal tides in the polar mesopause region. Randel et al. (2006) reported a sudden 


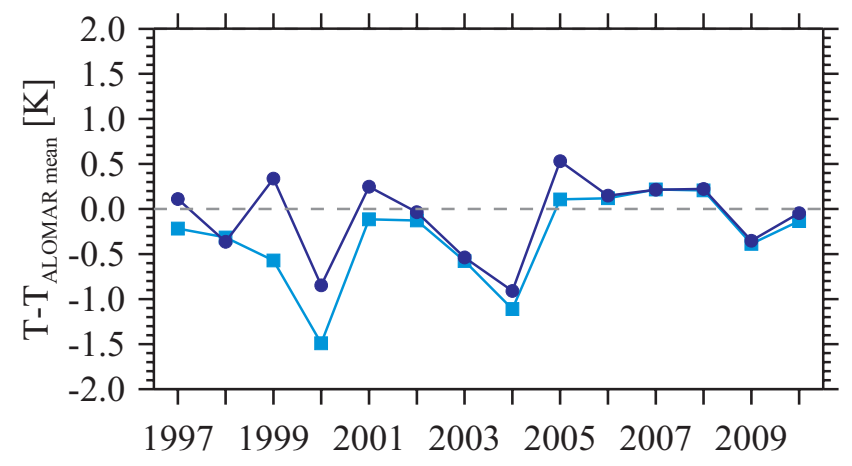

Fig. 10. Seasonal mean sampling of temperature at $83 \mathrm{~km}$ altitude during ALOMAR RMR-lidar measurements as determined by LIMA. Temperatures calculated solely for hours with lidar measurements are compared to entire means from 1 June to 15 August. Sampling curves are calculated for two data sets: long-term (blue circles) and high-sensitivity (light blue squares).

decrease of tropical stratospheric water vapor, tropopause temperature and ozone content starting 2001, which is explained by increasing Brewer-Dobson circulation. This could enhance extratropical stratospheric ozone which may be linked to increasing amplitudes of the semidiurnal tidal component. To what extent this might be relevant for polar latitudes remains speculation.

Tidal signatures in NLC parameters have also been observed at other fixed locations by lidar (Chu et al., 2003) and over larger areas by satellite (Shettle et al., 2002). Such variability could impact the interpretation of measurements which do not cover the full diurnal cycle. Visual NLC observations are limited by angular relationships between sun, cloud and observer to certain twilight conditions. Satellite instruments usually operate from sun synchronous orbits and hence observe NLC at two fixed local times, representing the ascending and descending nodes of the orbit. Additionally the orbit can shift over the lifetime of the satellite, thus producing a local time shift of the observations. Hence the interplay of tidal amplitudes and phases with the observation times might change the nature of a multi-year time series obtained from such measurements. To estimate the magnitude we applied the following method to our lidar data: We recalculated the tidal behavior of NLC occurrence and brightness for each year from the coefficients of the harmonic fits shown in Fig. 5 (mean value, 24- and 12-h oscillations). The results are shown at the left panels of Fig. 11 (black curves). Thereof we reconstructed several year-to-year variations which are shown at the right panels. At first all 24 local times per year were used. This results into the solid black curves which will be called RMR-curves as they represent the lidar obtained time series. At second single local times were chosen which are separated by $8 \mathrm{~h}$ from each other (04:00, 12:00, 20:00 LT). This results into the dashed colored time series and demonstrates the effect as clear as possible. At third we took the local times for ALOMAR overpasses of all NOAAsatellites operated between 1998 and 2009 contributing to the SBUV time series (Fig. 2 in DeLand et al., 2007; M. T. DeLand, private communication, 2009). This yields between one (1998) and four (2005) satellites, corresponding to 2 to 8 local times, per year and results into the dashed black curves which we call "SBUV" curves. In other words, all time series are based on RMR-lidar data but filtered by different local times.

As expected the time series for single local times show different mean levels. Additionally the year-to-year variations differ from the curves covering the full diurnal cycle and the 14-year tendency (linear regression) can be different for each local time. Just two examples: The 4 LT occurrence time series shows a decreasing behaviour which is not present in the time series containing all local times. The 12 LT brightness time series increases more or less steadily over the 14 years by $\sim 150 \%$ and differs substantially from the variation pattern when taking into account all local times.

Due to the combination of several local times per year the "SBUV" time series follow much closer the RMR-curves than the ones for single local times. The relative differences between both time series are up to $45 \%$ (occurrence) and $12 \%$ (brightness) for single years. We chose $\beta_{\text {tot }}$ for the brightness as it represents the integrated signal over the vertical cloud extension which compares better to satellite observations than the peak signal $\left(\beta_{\max }\right)$. The slopes, resulting from linear regressions, of the " $S B U V$ " curves are larger than the ones of RMR: for occurrence $0.30 \% /$ year compared to $0.11 \% /$ year, for brightness $0.50 \times 10^{-7} \mathrm{sr}^{-1} /$ year compared to $0.35 \times 10^{-7} \mathrm{sr}^{-1} /$ year. Hence the slopes generated from SBUV observation times overestimate the true behavior.

Our data set here shows that amplitudes as well as phases of NLC occurrence and brightness are not constant over the years. They rather vary in a different manner: amplitudes can change by a factor of more than 3 and phases show changes of up to $7 \mathrm{~h}$. To estimate the impact of this variability we repeated the procedure used for Fig. 11, but applied now the 14-year mean diurnal and semidiurnal coefficients (amplitudes and phases) instead of the actual ones for each individual year. The results are shown in Fig. 12. Comparing both figures we find slope differences (actual/mean coefficients) of $+8.6 \%$ (occurrence) and $+40.4 \%$ (brightness) for the "SBUV" time series. Fixing the coefficients of all years to the ones of a single year produces a substantial scatter of slopes, depending on the chosen year. Envelopes for the slope differences (actual/fixed coefficients) are: $-33.7 \%$ (year 2004) to $+126.3 \%$ (year 2009) for occurrence, $+16.6 \%$ (year 2001) to $+89.1 \%$ (year 1998) for brightness.

DeLand et al. (2007) and Shettle et al. (2009) showed for the SBUV time series brightness (albedo) and occurrence frequency trends of $+6.3 \% /$ decade (significant) and $+6.7 \% /$ decade (not significant), respectively, in the 64 $74^{\circ} \mathrm{N}$ latitude band. The SBUV data were adjusted using 


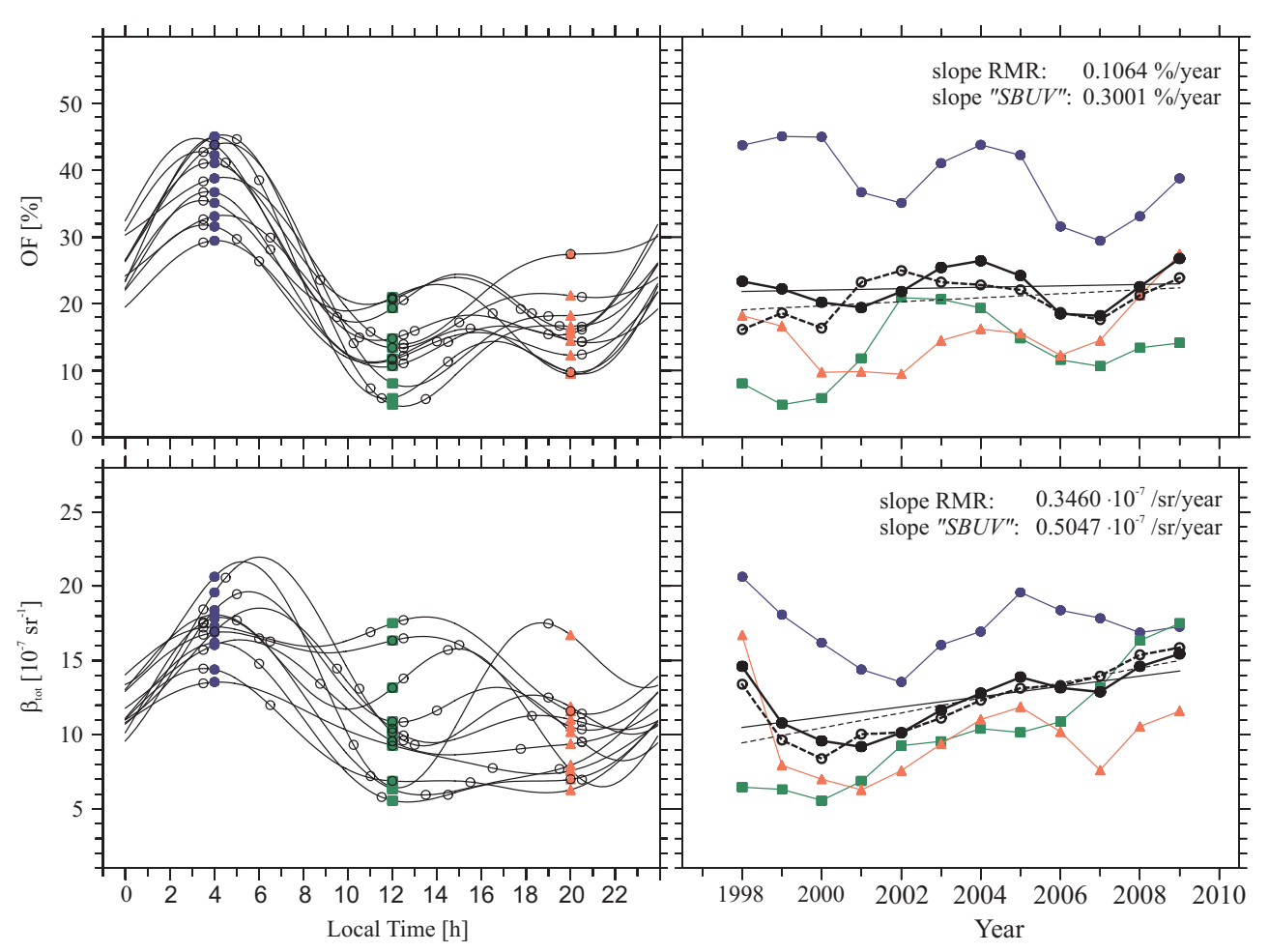

Fig. 11. Reconstructed local time and year-to-year variations of NLC occurrence (top) and brightness (bottom) for the ALOMAR RMR-lidar data set from 1997 to 2010. Left panels show the diurnal behavior for each year calculated from the harmonic fit coefficients (mean, 24-, 12-h) in Fig. 5 (black lines). ALOMAR overpasses of NOAA-satellites contributing to the SBUV time series between 1998 and 2009 are marked by open circles. Three single local times are marked by colored symbols. Right panels show the year-to-year behavior as calculated from the diurnal behavior for different local time filtering: all 24 local times = RMR-curve (black solid line and filled circles), NOAA local times = "SBUV"-curve (black dashed line and open circles), single local times (colored lines and symbols). Straight lines show the slopes of RMR- and " $S B U V$ "-curves as determined by linear regression. Based on 3 years running means for clouds above the long-term limit. For more details see text.

Table 1. Correlation between seasonal mean NLC parameters, solar activity and temperature at $83 \mathrm{~km}$ altitude for clouds above the long-term limit $\left(\beta_{\max }>4\right)$. Numbers are for the whole time series and reduced data sets (in brackets): Lyman- $\alpha$ dependencies without 2005-2008, temperature dependencies without 1998. Units: occurrence [\%], brightness $\left[10^{-10} \mathrm{~m}^{-1} \mathrm{sr}^{-1}\right]$, altitude [km], Lyman- $\alpha$ $\left[10^{11}\right.$ photons s $\left.{ }^{-1} \mathrm{~cm}^{-1}\right]$, temperature $[\mathrm{K}]$. Lyman- $\alpha$ data are taken from http $: / /$ lasp.colorado.edu/lisird/lya/. Temperatures are calculated by LIMA for times of lidar measurements. Slopes for the linear regressions are only given for significant correlations.

\begin{tabular}{llrrr}
\hline $\mathrm{X}$ & $\mathrm{Y}$ & Corr. Coeff. & Signif. & Slope \\
\hline Occurrence & Lyman- $\alpha$ & $-0.28(-0.73)$ & $(95 \%)$ & $(-7.92)$ \\
Brightness $\left(\beta_{\max }\right)$ & Lyman- $\alpha$ & $-0.54(-0.73)$ & $95 \%(95 \%)$ & $-1.49(-2.18)$ \\
Altitude $\left(z_{c}\right)$ & Lyman- $\alpha$ & $+0.58(+0.68)$ & $95 \%(95 \%)$ & $+0.25(+0.28)$ \\
Occurrence & $\mathrm{T}(83 \mathrm{~km})$ & $-0.63(-0.77)$ & $95 \%(99 \%)$ & $-3.80(-5.87)$ \\
Brightness $\left(\beta_{\max }\right)$ & $\mathrm{T}(83 \mathrm{~km})$ & $-0.27(-0.20)$ & & \\
Altitude $\left(z_{c}\right)$ & $\mathrm{T}(83 \mathrm{~km})$ & $+0.43(+0.62)$ & $(95 \%)$ & $(+0.19)$ \\
\hline
\end{tabular}

a method which qualitatively reflects the mean tidal variability patterns observed above ALOMAR (Fiedler et al., 2005). SBUV trends are based on $\sim 28$ years and consider solar cycle effects and thus cannot be directly compared to our "SBUV"/RMR calculations above. However, we note that the slope differences arising solely from different local time filtering of an identical 14-year data set exceed the trend val- ues substantially. The inclusion of variable amplitudes and phases as determined from our observations between 1997 and 2010 results into an overestimation of slopes for SBUV observation times for both occurrence $(+8.6 \%)$ and brightness $(+40.4 \%)$, compared to the 14-year mean amplitudes and phases. This indicates that long-term NLC observations could be impacted by non-stable tidal parameters. To which 


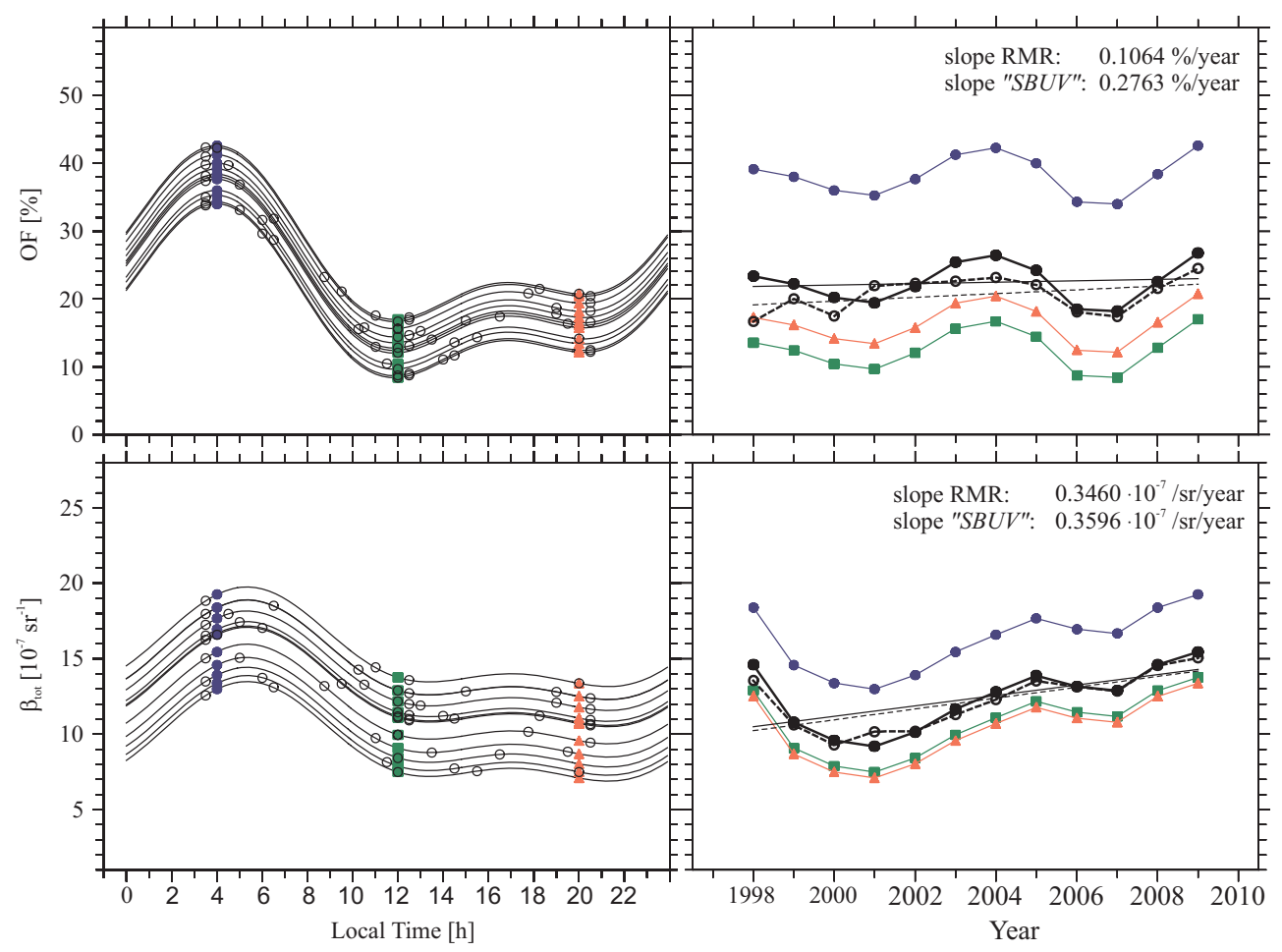

Fig. 12. Same as Fig. 11, but the diurnal behavior for each year was calculated from the 14-year mean fit coefficients (24-, 12-h).

extent remains speculation as long as the actual amplitudes and phases, especially in the past, are unknown.

Constraints which might weaken the relevance of the above results to trends in SBUV time series are: For our analysis we used NLC above the long-term limit $\left(\beta_{\max }>4\right)$ but the SBUV instruments are sensitive to only brightest clouds, cf. DeLand et al. (2007). Limitation of our data to solely strong clouds would considerably reduce the data amount as well as the significance of tidal parameters. Note that even our strong NLC $\left(\beta_{\max }>13\right)$ occur twice as frequently compared to cloud detections by SBUV instruments (cf. Fig. 7 in Fiedler et al. (2009)), which suggests that SBUV detects only the strongest part of our strong clouds class definition. Furthermore the variability of tidal parameters could change with longitude which in turn would result into a different zonal mean behavior as seen by SBUV.

\subsection{Correlations}

Solar activity variation is expected to impact NLC formation primarily due to Lyman- $\alpha$ induced photolysis of water vapor and temperature variation in the mesopause region. Such temperature changes are primarily caused by solar heating processes in the ultraviolet, which are included in our LIMA version. Figure 13 shows the correlation between NLC occurrence from lidar and solar activity and temperature at $83 \mathrm{~km}$ from LIMA, respectively. Taking into account the whole time series from 1997 to 2010, we find no significant anti-correlation between occurrence and solar Lyman- $\alpha$ radiation. When removing the years 2005-2008 from the analysis the anti-correlation becomes significant on $95 \%$ level. During these years cloud occurrence and Lyman- $\alpha$ radiation were almost in-phase. On the other hand the anti-correlation between NLC occurrence and temperature is significant for the whole data set, and is even improving to $99 \%$ level when removing the single outlier 1998. This suggests that thermal conditions play a major role for the existence of ice particles, and dominate the pure Lyman- $\alpha$ influence on water vapor during certain years. This is supported by mesospheric water vapor measurements with a microwave instrument at ALOMAR. Hartogh et al. (2010) find during summer generally decreasing $\mathrm{H}_{2} \mathrm{O}$ mixing ratios between 1996 and 2006 up to an altitude of $80 \mathrm{~km}$, which is the uppermost altitude available from the instrument. The overall decrease during these 11 years is $15 \%$ in contrast to only $4.5 \%$ decrease between solar minimum and maximum due to the sensitivity of $\mathrm{H}_{2} \mathrm{O}$ to Lyman- $\alpha$ radiation.

Table 1 gives an overview of several correlations investigated. The NLC brightness is anti-correlated to Lyman- $\alpha$ and shows no interrelationship to temperature. The altitude is positively correlated to both Lyman- $\alpha$ and temperature (single outlier removed).

Lübken et al. (2009) investigated for 46 years (19612008) the seasonal mean NLC parameter sensitivity to solar Lyman- $\alpha$ radiation and temperature using a model for both background atmosphere and ice particles (LIMA/ICE). 

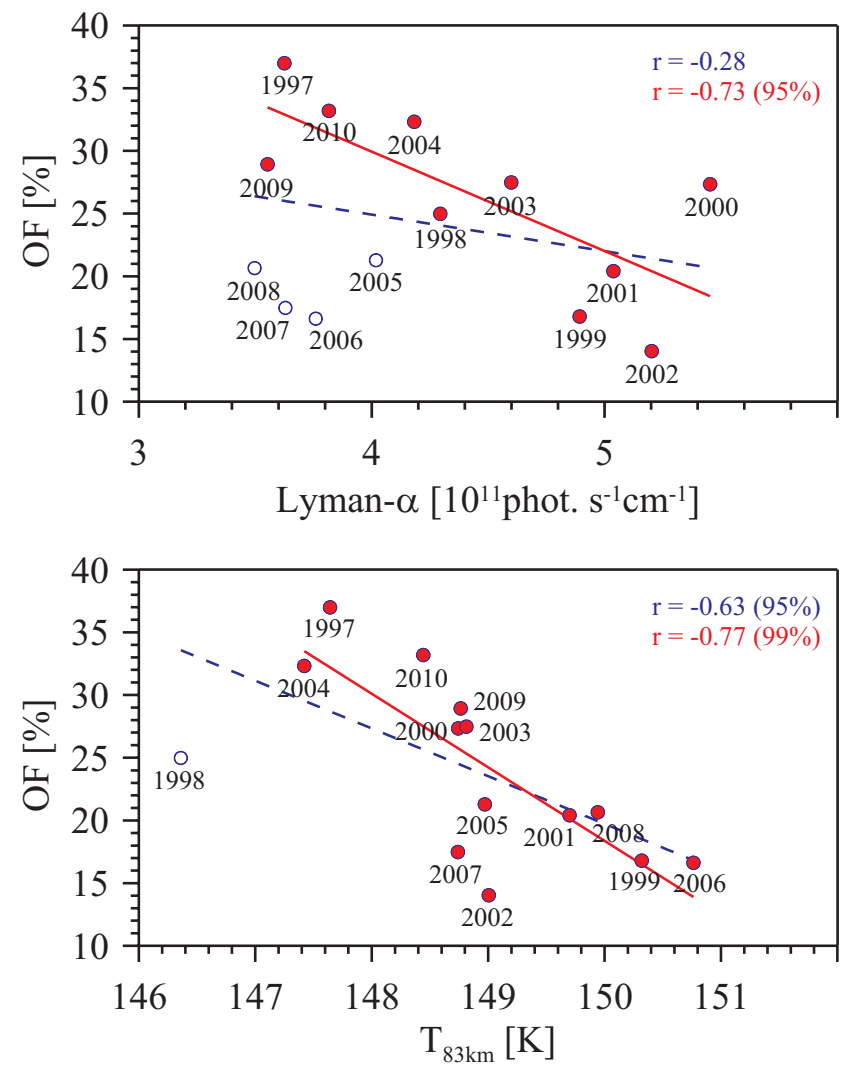

Fig. 13. Occurrence of NLC above the long-term limit $\left(\beta_{\max }>4\right)$ at ALOMAR as function of solar activity (top) and temperature at $83 \mathrm{~km}$ altitude (bottom). Lyman- $\alpha$ data are taken from http://lasp. colorado.edu/lisird/lya/ and averaged over the NLC season (1 June15 August). Temperatures are calculated by LIMA for times of lidar measurements. Blue colors/dashed lines represent the whole data set covering 14 years, whereas the outlier adjusted data subsets are indicated in red/solid lines. Significance levels of the correlation coefficients are given in brackets.

In general we find comparable relationships, here for observed NLC. Weaker or even no correlations with respect to Lyman- $\alpha$ in Lübken et al. (2009) are probably caused by the missing solar heating processes in the mesopause region in their LIMA version. The solar cycle information inherent in the assimilated tropospheric/stratospheric ECMWF data will impact mesospheric altitudes through vertical coupling, but certainly to a much lesser degree than direct heating processes. It is interesting that our data does not show a correlation between observed NLC brightness and modelled temperature, while there is a significant anticorrelation present for the modelled NLC (c.f. Lübken et al., 2009). In our data set the altitude variation with temperature at $83 \mathrm{~km}$ is $+0.19 \mathrm{~km} / \mathrm{K}$ (year 1998 removed), which is slightly smaller than calculated by different models: CARMA: $+0.25 \mathrm{~km} / \mathrm{K}$ to $+0.53 \mathrm{~km} / \mathrm{K}$ (Lübken et al., 2007), LIMA/ICE: $+0.26 \mathrm{~km} / \mathrm{K}$ (Lübken et al., 2009). However, these values do not contain the Lyman- $\alpha$ influence on the mesopause region. Our measured NLC altitudes show correlations to both Lyman- $\alpha$ and temperature. At the same time Lyman- $\alpha$ and temperature show no significant relationship over the 14 years. Therefore it is possible that Lyman- $\alpha$ masks the pure temperature influence which in turn could explain the lower altitude variation with temperature in our data set.

It appears complex to determine which part of the year-toyear NLC variation is caused by solar activity, as solar radiation acts on both water vapor and temperature. Additionally the ice particles are modulated by atmospheric dynamics which altogether results into considerable natural variability.

\section{Conclusions}

We presented results from a multi-year NLC data set obtained by ground-based lidar at ALOMAR. The time series covers 14 years, starting 1997, and contains $\sim 1865 \mathrm{~h}$ NLC detections during a total of $\sim 4340$ measurement hours. ALOMAR MF-radar and LIMA-model data were used to characterize the background atmosphere during lidar measurements.

When using atmospheric data solely determined for hours with lidar measurements and sorted for NLC yes/no cases we find a clear separation of seasonal mean temperature and horizontal winds at $83 \mathrm{~km}$ altitude: During each single year it was colder and the winds were stronger westward during NLC observations compared to the absence of NLC. This separation is also visible for the meridional wind, but not during all years. 14-years mean differences between NLC presence and absence are $-2 \mathrm{~K}$ for temperature, $-9 \mathrm{~m} / \mathrm{s}$ to $-10 \mathrm{~m} / \mathrm{s}$ for zonal wind and $-2 \mathrm{~m} / \mathrm{s}$ to $-5 \mathrm{~m} / \mathrm{s}$ for meridional wind. The wind separation is a robust feature as it shows up in measurement as well as model. The temperature separation seems plausible as lower temperatures support the existence of ice particles. We conclude that the LIMA-model is able to reproduce the background atmosphere to a sufficient degree on hourly resolution, at least on a statistical average over the NLC season.

The lidar sampling quality during each year was investigated regarding the multi-year mean diurnal and seasonal variations of NLC occurrence, altitude and brightness. It turned out that for each NLC parameter the general variation patterns of the long-term data set are not significantly affected by the sampling. From the comparison of yearly mean temperatures calculated by LIMA solely for lidar measurement hours with entire means over the NLC season we follow that our NLC time series is most likely not biased by different sampling of the temperature structure at NLC altitudes.

We find no statistically significant relation between NLC occurrence and solar Lyman- $\alpha$ radiation when using the whole time series from 1997 to 2010 . The reason is, that between 2005 and 2008 cloud occurrence and Lyman- $\alpha$ 
radiation were almost in-phase, contrary to the other years. On the other hand the relationship to local temperature at NLC altitudes as calculated by LIMA is much stronger: The anti-correlation between NLC occurrence and temperature is significant for the whole data set, and is even improving to $99 \%$ level when removing the single outlier 1998. This suggests that thermal conditions play a major role for the existence of ice particles which dominates the pure Lyman- $\alpha$ influence on water vapor during certain years. We find the seasonal mean NLC altitudes to be correlated to both Lyman- $\alpha$ radiation and temperature. The altitude variation with temperature at $83 \mathrm{~km}$ is $+0.19 \mathrm{~km} / \mathrm{K}$ (year 1998 removed).

Our data set shows pronounced persistent variations of NLC properties with local time, which indicates a strong tidal influence on ice particles above ALOMAR. Faint clouds occur most often compared to the other cloud classes but the occurrence variability is largest for strong clouds. The cloud water content varies by a factor of 2.8 over the diurnal cycle. Depending on the NLC parameter, diurnal and semidiurnal amplitudes and phases have different and partly strong year-to-year variations. Most striking features are shown by the NLC brightness: The semidiurnal amplitude has very low values during solar maximum and is over a period of 10 years significantly anti-correlated to Lyman- $\alpha$ radiation. The diurnal phase increases monotonically over the whole time series. In general, amplitudes as well as phases of NLC parameters are not constant over the years. They rather vary in a different manner, amplitudes can change by a factor of more than 3 and phases show changes up to $7 \mathrm{~h}$. Long-term NLC observations which do not cover the full diurnal cycle could be impacted by non-stable tidal parameters but to which extent remains speculation as long as the actual amplitudes and phases are unknown.

Acknowledgements. We gratefully acknowledge the support of the ALOMAR staff in helping to accumulate the extensive data set of NLC observations. The observations were also supported by a huge number of voluntary lidar operators. This work received research funding from the European Community's 6th Framework Program under the project "ALOMAR eARI" (RITA-CT-2003-506208). This project is supported by the Deutsche Forschungsgemeinschaft under the CAWSES SPP grant LU 1174/3-1 (SOLEIL).

Edited by: W. Ward

\section{References}

Alpers, M., Gerding, M., Höffner, J., and von Zahn, U.: NLC particle properties from a five-color lidar observation at $54^{\circ} \mathrm{N}, \mathrm{J}$. Geophys. Res., 105, 12235-12240, doi:10.1029/2000JD900132, 2000.

Backhouse, T. W.: The luminous cirrus clouds of June and July, Meteorol. Mag., 20, p. 133, 1885.

Baumgarten, G., Fricke, K. H., and von Cossart, G.: Investigation of the shape of noctilucent cloud particles by polar- ization lidar technique, Geophys. Res. Lett., 29(13), 1630, doi:10.1029/2001GL013877, 2002.

Baumgarten, G., Fiedler, J., Lübken, F.-J., and von Cossart, G.: Particle properties and water content of noctilucent clouds and their interannual variation, J. Geophys. Res., 113, D06203, doi:10.1029/2007JD008884, 2008.

Berger, U.: Modeling of middle atmosphere dynamics with LIMA, J. Atmos. Solar Terr. Phys., 1170-1200, doi:10.1016/j.jastp.2008.02.004, 2008.

Berger, U. and von Zahn, U.: Icy particles in the summer mesopause region: Three-dimensional modeling of their environment and two-dimensional modeling of their transport, J. Geophys. Res., 107(A11), 1366, doi:10.1029/2001JA000316, 2002.

Berger, U. and von Zahn, U.: Three-dimensional modeling of the trajectories of visible noctilucent cloud particles: An indication of particle nucleation well below the mesopause, J. Geophys. Res., 112, D16204, doi:10.1029/2006JD008106, 2007.

Chu, X., Gardner, C. S., and Roble, R.: Lidar studies of interannual, seasonal and diurnal variations of polar mesospheric clouds at the South Pole, J. Geophys. Res., 108(D8), 8447, doi:10.1029/2002JD002524, 2003.

DeLand, M. T., Shettle, E. P., Thomas, G. E., and Olivero, J. J.: Latitude-dependent long-term variations in polar mesospheric clouds from SBUV version 3 PMC data, J. Geophys. Res., 112, D10315, doi:10.1029/2006JD007857, 2007.

Donahue, T. M., Guenther, B., and Blamont, J. E.: Noctilucent clouds in daytime: Circumpolar particulate layers near the summer mesopause, J. Atmos. Sci., 26, 1205-1209, 1972.

Fiedler, J., Baumgarten, G., and von Cossart, G.: Mean diurnal variations of noctilucent clouds during 7 years of lidar observations at ALOMAR, Ann. Geophys., 23, 1175-1181, doi:10.5194/angeo-23-1175-2005, 2005.

Fiedler, J., Baumgarten, G., and Lübken, F.-J.: NLC observations during one solar cycle above ALOMAR, J. Atmos. Solar Terr. Phys., 424-433, doi:10.1016/j.jastp.2008.11.010, 2009.

Fogle, B. and Haurwitz, B.: Noctilucent clouds, Space Sci. Rev., 6, 279-340, doi:10.1007/BF00173768, 1966.

Gadsden, M.: Noctilucent clouds, Journal of the British Astronomical Association, 99, 210-214, 1989.

Gerding, M., Höffner, J., Rauthe, M., Singer, W., Zecha, M., and Lübken, F.-J.: Simultaneous observation of noctilucent clouds, mesospheric summer echoes, and temperature at a midlatitude station $\left(54^{\circ} \mathrm{N}\right)$, J. Geophys. Res., 112, D12111, doi:10.1029/2006JD008135, 2007.

Hansen, G., Servazi, M., and von Zahn, U.: First detection of a noctilucent clouds by lidar, Geophys. Res. Lett., 16, 1445-1448, doi:10.1029/GL016i012p01445, 1989.

Hartogh, P., Sonnemann, G. R., Grygalashvyly, M., Song, L., Berger, U., and Lübken, F.-J.: Water vapor measurements a ALOMAR over a solar cycle compared with model calculations by LIMA, J. Geophys. Res., 115, D00I17, doi:10.1029/2009JD012364, 2010.

Hervig, M., Thompson, R. E., McHugh, M., Gordley, L. L., Russel III, J. M., and Summers, M. E.: First confirmation that water ice is the primary component of polar mesospheric clouds, Geophys. Res. Lett., 28, 971-974, doi:10.1029/2000GL012104, 2001.

Höffner, J., Fricke-Begemann, C., and Lübken, F.-J.: First observations of noctilucent clouds by lidar at Svalbard, $78^{\circ} \mathrm{N}$, At- 
mos. Chem. Phys., 3, 1101-1111, doi:10.5194/acp-3-1101-2003, 2003.

Jesse, O.: Auffallende Abenderscheinungen am Himmel, Meteorol. Zeitung, 2, 311-312, 1885.

Jesse, O.: Die Höhe der leuchtenden Nachtwolken, Astron. Nachrichten, 140, 161-168, 1896.

Kiliani, J., Lübken, F.-J., Berger, U., Baumgarten, G., and Hoffmann, P.: Modelling of NLC particle history with LIMA/ICE, EGU General Assembly, Geophys. Res. Abstracts, 13, EGU2011-8576, 2011.

Kirkwood, S., Dalin, P., and Réchou, A.: Noctilucent clouds observed from the UK and Denmark - trends and variations over 43 years, Ann. Geophys., 26, 1243-1254, doi:10.5194/angeo-261243-2008, 2008.

Klekociuk, A. R., Morris, R. J., and Innis, J. L.: First Southern Hemisphere common-volume measurement of PMC and PMSE, Geophys. Res. Lett., L24804, doi:10.1029/2008GL035988, 2008.

Langer, M., Müller, K. P., and Fricke, K. H.: Rayleigh lidar detection of aerosol echoes from noctilucent cloud altitudes at the Arctic circle, Geophys. Res. Lett., 22, 381-384, doi:10.1029/94GL02903, 1995.

Lean, J. L., Rottman, G. J., Kyle, H. L., Woods, T. N., Hickey, J. R., and Puga, L. C.: Detection and parameterization of variations in solar mid- and near-ultraviolet radiation (200-400 nm), J. Geophys. Res., 102, 29939-29956, doi:10.1029/95GL03093, 1997.

Leslie, R. C.: Sky glows, Nature, 32, p. 245, 1885.

Lübken, F.-J.: Thermal structure of the arctic summer mesosphere, J. Geophys. Res., 104, 9135-9149, doi:10.1029/1999JD900076, 1999.

Lübken, F.-J., Fricke, K. H., and Langer, M.: Noctilucent clouds and the thermal structure near the Arctic mesopause in summer, J. Geophys. Res., 101, 9489-9508, doi:10.1029/96JD00444, 1996.

Lübken, F.-J., Rapp, M., and Strelnikova, I.: The sensitivity of mesospheric ice layers to atmospheric background temperatures and water vapor, Adv. Space Res., 40, 794-801, doi:10.1016/j.asr.2007.01.014, 2007.

Lübken, F.-J., Berger, U., and Baumgarten, G.: Stratospheric and solar cycle effects on long-term variability of mesospheric ice clouds, J. Geophys. Res., D00I06, doi:10.1029/2009JD012377, 2009.

Marsh, D. R., Garcia, R. R., Kinnison, D. E., Boville, B. A., Sassi, F., Solomon, S. C., and Matthes, K.: Modeling the whole atmosphere response to solar cycle changes in radiative and geomagnetic forcing, J. Geophys. Res., 112, D23306, doi:10.1029/2002JD002364, 2007.

Nussbaumer, V., Fricke, K. H., Langer, M., Singer, W., and von Zahn, U.: First simultaneous and common volume observations of noctilucent clouds and polar mesosphere summer echoes by lidar and radar, J. Geophys. Res., 101, 19161-19167, doi:10.1029/96JD01213, 1996.

Randel, W. J., Wu, F., Vömel, H., Nedoluha, G. E., and Forster, P.: Decreases in stratospheric water vapor after 2001: Links to changes in the tropical tropopause and the Brewer-Dobson circulation, J. Geophys. Res., 111, D12312, doi:10.1029/2005JD006744, 2006.

Rapp, M. and Thomas, G. E.: Modeling the microphysics of mesospheric ice particles: Assessment of current capabilities and basic sensitivities, J. Atmos. Solar Terr. Phys., 68, 715-744, doi:10.1016/j.jastp.2005.10.015, 2006.

Rauthe, M., Gerding, M., Höffner, J., and Lübken, F.-J.: Lidar temperature measurements of gravity waves over Kühlungsborn $\left(54^{\circ} \mathrm{N}\right)$ from 1 to $105 \mathrm{~km}$ : A winter-summer comparison, J. Geophys. Res., 111, D24108, doi:10.1029/2006JD007354, 2006.

Romejko, V. A., Dalin, P. A., and Pertsev, N. C.: Forty years of noctilucent cloud observations near Moscow: Data base and simple statistics, J. Geophys. Res., 108(D8), 8443, doi:10.1029/2002JD002364, 2003.

Schmidt, H., Brasseur, G., Charron, M., Manzini, E., Giorgetta, M., Diehl, T., Fomichev, V., Kinnison, D., Marsh, D., and Walters, S.: The HAMMONIA chemistry climate model: sensitivity of the mesopause region to the 11-year cycle and $\mathrm{CO}_{2}$ doubling, $\mathrm{J}$. Climate, 19, 3903-3931, 2006.

Shettle, E. P., Thomas, G. E., Olivero, J. J., Evans, W. F. J., Debestrian, D. J., and Chardon, L.: Three-satellite comparison of polar mesospheric clouds: Evidence for long-term change, J. Geophys. Res., 107(D12), ACL 2, 1-6, doi:10.1029/2001JD000668, 2002.

Shettle, E. P., DeLand, M. T., Thomas, G. E., and Olivero, J. J.: Long term variations in the frequency of polar mesospheric clouds in the Northern Hemisphere from SBUV, Geophys. Res. Lett., 36, L02803, doi:10.1029/2008GL036048, 2009.

Singer, W., Keuer, D., and Eriksen, W.: The ALOMAR MF radar: Technical design and first results, in: Proceedings of the 13th ESA Symposium on European Rocket and Balloon Programmes and Related Research, Oeland, Sweden (ESA SP-397), edited by: Kaldeich-Schürmann, B., ESA SP-397, 101-104, 1997.

Stevens, M. H., Siskind, D. E., Eckermann, S. D., Coy, L., McCormack, J. P., Englert, C. R., Hoppel, K. W., Nielsen, K., Kochenash, A. J., Hervig, M. E., Randall, C. E., Lumpe, J., Bailey, S. M., Rapp, M., and Hoffmann, P.: Tidally induced variations of polar mesospheric cloud altitudes and ice water content using a data assimilation system, J. Geophys. Res., 115, D18209, doi:10.1029/2009JD013225, 2010.

Thayer, J. P., Rapp, M., Gerrard, A. J., Gudmundsson, E., and Kane, T. J.: Gravity wave influences on Arctic mesospheric clouds as determined by a Rayleigh lidar at Sondrestrom, Greenland, J. Geophys. Res., 108(D8), 8449, doi:10.1029/2002JD002363, 2003.

Thomas, G. E.: Solar Mesospheric Explorer measurements of polar mesospheric clouds (noctilucent clouds), J. Atmos. Terr. Phys., 46, 819-824, 1984.

Thomas, G. E., McPeters, R. D., and Jensen, E. J.: Satellite observations of polar mesospheric clouds by Solar Backscattered Ultraviolet spectral radiometer: Evidence of a solar cycle dependence, J. Geophys. Res., 96, 927-939, doi:10.1029/90JD02312, 1991.

Thomas, G. E.: Is the polar mesosphere the miner's canary of global change?, Adv. Space Res., 18, 149-158, 1996.

Thomas, G. E., Olivero, J. J., DeLand, M., and Shettle, E. P.: A response to the article by U. von Zahn, "Are noctilucent clouds truly a "miner's canary" for global change?", Trans. Am. Geophys. Union (EOS), 84, 352-553, doi:10.1029/2003EO360008, 2003.

Turco, R. P., Toon, O. B., Whitten, R. C., Keesee, R. G., and Hollenbach, D.: Noctilucent clouds: Simulation studies of their genesis, properties and global influences, Planet. Space Sci., 30, 11471181, doi:10.1016/0032-0633(82)90126-X, 1982. 
Vestine, E. H.: Noctilucent clouds, J. Roy. Astronom. Soc. Cnd., 18, 249-272, 303-317, 1934.

von Cossart, G., Fiedler, J., and von Zahn, U.: Size distributions of NLC particles as determined from 3-color observations of NLC by ground-based lidar, Geophys. Res. Lett., 26, 1513-1516, doi:10.1029/1999GL900226, 1999.

von Zahn, U.: Are noctilucent clouds truly a "miner's canary" for global change?, Trans. Am. Geophys. Union (EOS), 84, 261264, doi:10.1029/2003EO280001, 2003. von Zahn, U., von Cossart, G., Fiedler, J., Fricke, K. H., Nelke, G., Baumgarten, G., Rees, D., Hauchecorne, A., and Adolfsen, K.: The ALOMAR Rayleigh/Mie/Raman lidar: objectives, configuration, and performance, Ann. Geophys., 18, 815-833, doi:10.1007/s00585-000-0815-2, 2000.

Wegener, A.: Die Erforschung der obersten Atmosphärenschichten, Gerlands Beiträge zur Geophysik, 11, 104-124, 1912.

Witt, G.: Height, structure and displacements of noctilucent clouds, Tellus, 14, 1-18, 1962. 